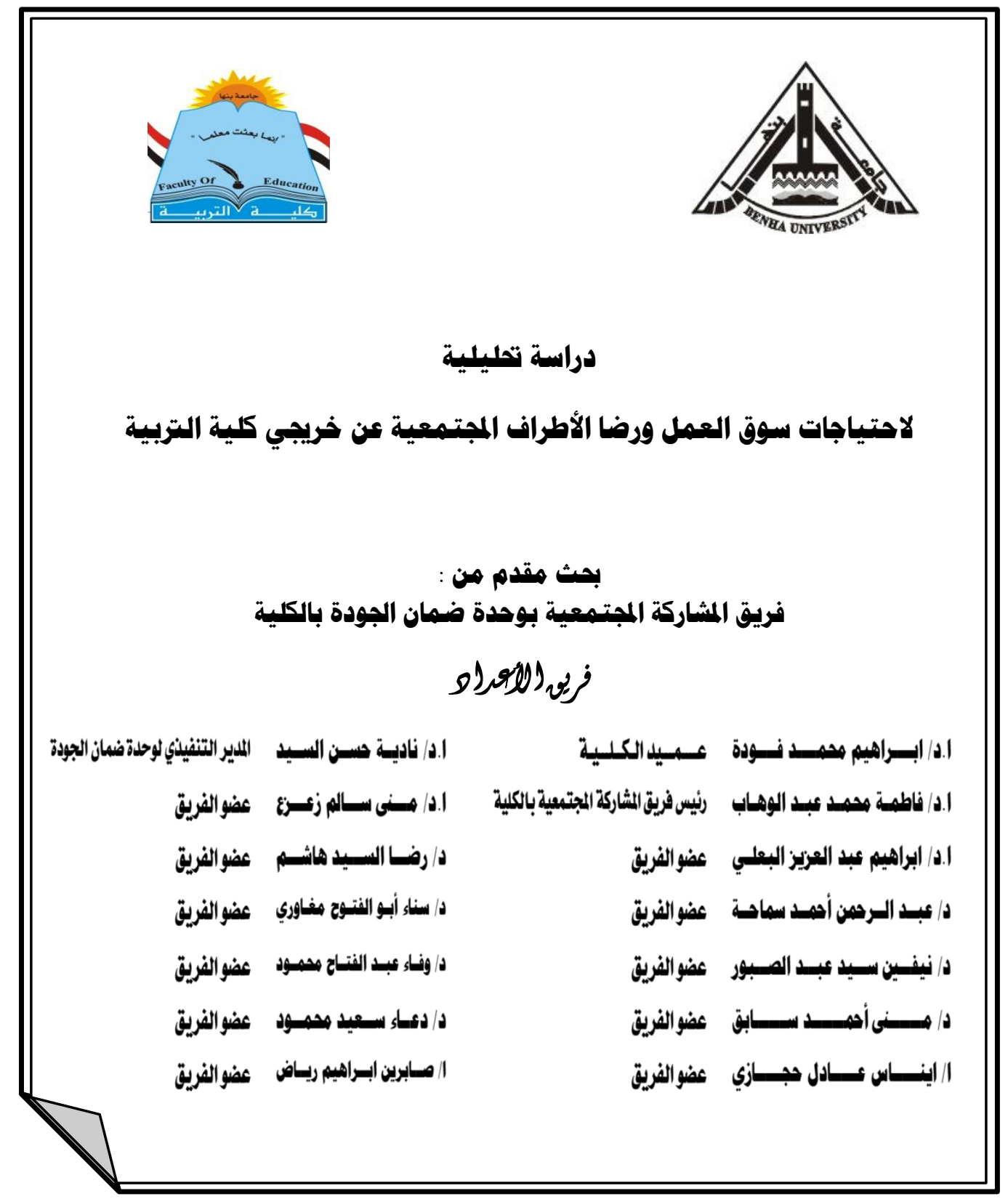




\section{دراسة تحليلية لاحتياجات سوق العمل ورضا الأطراف الجتمهعية عن خريجي كلية التربية}

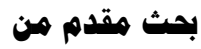

فريق المشاركة المجتمعية بوحدة ضمان الجودة بالكاية هنية

\section{פ}

1. ـ/ ناديسة حسن السـيد الملير التنفيذي لوحدة ضمان الجودة

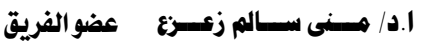

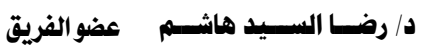

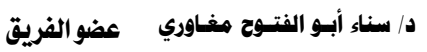

$$
\begin{aligned}
& \text { د/ وفساء عبـد الفتساح همهـود عضو الفريق } \\
& \text { د/ دعسكاء سـعيد هممسود عضو الفريق } \\
& \text { | مسابرين ابـراهيم ريساض عضو الفريق }
\end{aligned}
$$

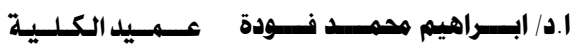

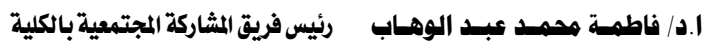

ا.د/ ابراهيم عبد العزيز البعلـي عضو الفريق

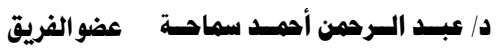

د/ نيفـين سـيد عبــد الصـبور عضو الفريق

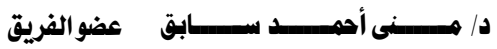

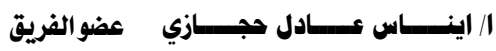

\section{همبنة:}

تعد كليات التربية من أهم المؤسسات التعليمية ، إذ أن الكلية معطاة لها التقة والمسئولية بتربية وإعداد الثباب مهنياً وأكاديميا وثقافيا لإدارة شئون الدولة والمجتمع الذي ينتمي إليه . وتعد كليات التربية من المؤسسات التعليمية المهمة في تتمية القوي البشرية المنتجة وذلك من خلال تزوبد طلابها بالقيم والاتجاهات والمعلومات والمعارف التي تمكنهم من الابتكار والمساهمة الإيجابية في صنع المستقبل، إذ تضطلع بإعداد وتخريج أعداد كبيرة من المعلمين سنوباً للعمل في مختلف مراحل التعليم قبل الجامعي.

وتضطلع- أيضاً - كليات التربية بتكوين وإعداد الباحثين في برنامج الدراسات العليا

التي تغطي مختلف التخصصات التي يحتاجها المجتمع • وبمكن لهؤلاء الباحثين بكفاياتهم البحثية والعلمية المكتسبة من برنامج الإعداد أن يقوموا بدور فعال في الوفاء باحتياجات القطاعات التربوبة والتعليمية على المستوبات التخطيطية والإشرافية والاستشارية والبحثية)

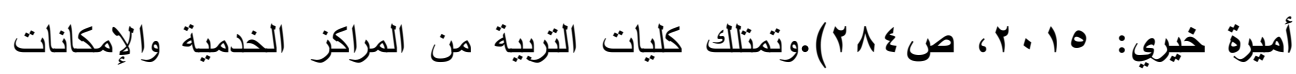
البشرية العلمية ما يجعلها قادرة علي القيام بدور فاعل في مجالات التتمية المهنية والاستشارات التربوبة للمؤسسات التعليمية والمدارس الحكومية والأهلية بمختلف مراحلها. 
وبذلك، كلية التربية من الكليات التي لها دور كبير وإيجابي وفعال في خدمة البيئة، فهي أداة من أدوات المجتمع الأساسية التي تعني بتطوير العلم والمعرفة من أجل النهوض ولئ فيله بمجتمعها وحل مشاكله ومواجهة التحديات التي تواجهه مما يجعلها تتفتح على سوق العمل التربوي فتتحسس آماله، وتلبى احتياجاته.

وعند الحديث عن سوق العمل، فلابد من تتاول العلاقات بين الراغبين في البيع والراغبين في الثراء، وبناء علي ذلك توجد علاقات منافسة بين الراغبين في البيع والراغبين

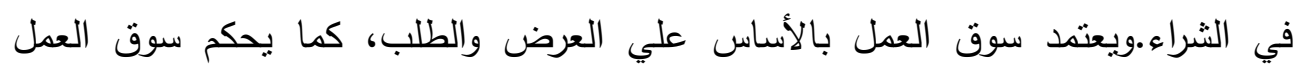
مجموعة من الآليات الثقافية والمؤسسية والسياسية، وتشكل هذه الآليات ما يعرف بتنظيم

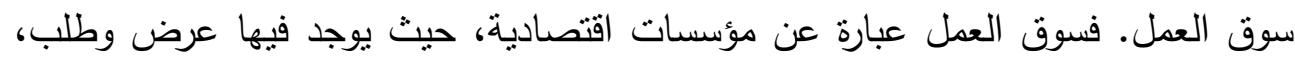
وتقاعل بين الباحثين عن فرص العمل وبين المؤسسات التي تبحث عن عمال( أمل رضا:

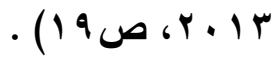

ونظراً لكون العلاقة بين كليات التربية وسوق العمل التربوي- في ظل مجتمع المعرفة- تعد ذات طابعاً ديناميكياً؛ فإن نجاح كليات التربية يقاس بسرعة استجابتها

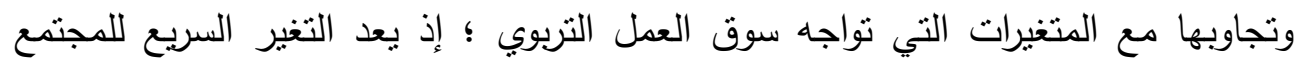
المعاصر مقارنة بالتغير البطئ الذي تتسم به عمليات التغيير التربوي المحكومة بالقواعد

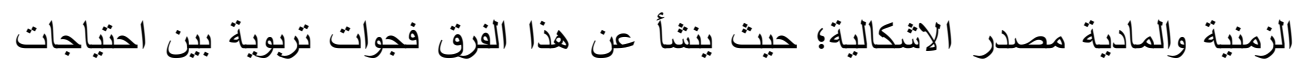
سوق العمل التربوي وتطلعاته، وأداء مؤسساته التربوية. وبناءً على ذلك فإنه على كليات التربية سد هذه الفجوات، وتلبية احتياجات سوق العمل التربوي وتحقيق التواصل الفعال بينها وبين الأطراف المجتمعية المستقيدة من الخدمة .

\section{هشكلة الدراسة}

\section{وفي ضوء ما سبق، يمكن صياغة مشكلة الاراسة في الأسئلة الآتية:}

ما احتياجات سوق العمل بمحافظة القليوبية من خدمات كلية التربية جامعة بنها؟ ما مستوى رضا الأطراف المجتمعية حول الخدمات التربوية التي تقدمها كلية 
• ما الروئة المقترحة لتحقيق التواصل الفعال بين كليات التربيةوالمستفدين من

\section{الخدمة؟}

\section{أهسداف الدراسة}

تسعى الدراسة إلى تحقيق الأهداف الآتية :

التعرف على البرامج التي تقدمها كليات التربية.

اسـنطلاع رأي الأطـراف المجتمعيـة حـول الخـدمات التربويـة التي تقدمها الكليـة

للمجنمع.

تحديد احتياجات سوق العمل من الخدمات والبرامج التي تقدمها الكلية.

الكثف عن واقع المشاركة المجتمعية بين كليات التربية وسوق العمل التربوي. وضع رؤية مقترحة لتحقيق التواصل الفعال بين كليات التربية وسوق العمل التربوي

\section{أهـميــة الدراسة وفية}

\section{تتبثق الدراسة أهميتها من خلال النقاط الآتية:}

تأكيد الهيئات والمنظمات الدولية الخاصة بالجودة والاعتماد علي ضرورة وجود مشاركة فعالة ومؤثزة بين كليات التزبية والأطراف المجتمعية المحيطة بها من أجل مخرج تعليمي

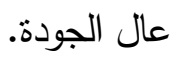

• التأكيد على كون كليات التربية تقدم روئية مقترحة لتحقيق التواصل الفعال بينها

$$
\text { وبين سوق العمل التربوي. }
$$

دور كليات التربية في تحقيق التتمية البشرية وتوفير كوادر بشرية قادرة على قيادة

$$
\text { التطوير فى المحافظة }
$$

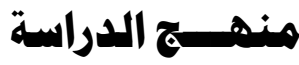

تقتضـي طبيعـة الدراسـة استخدام المسنهج الوصسفي: "الذي يتمثنل في مجموعـة

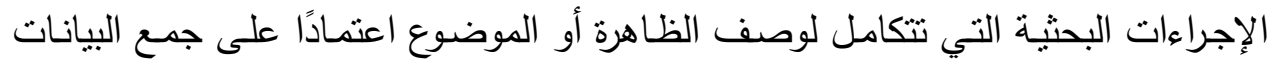

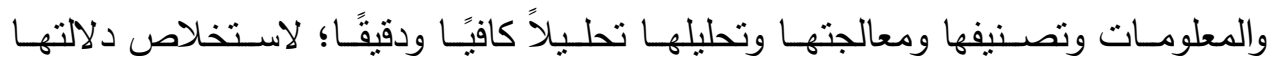
والوصول إلى نتائج أو تعميمات عن الظاهرة أو الموضوع محل البحث" (محمد السيد:

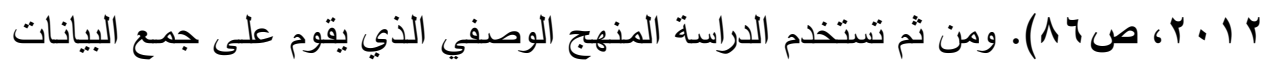


والمعلومـات المتعلقة بطبيعـة العلاقـة بين كليـات التربيـة وسـوق العمل التربوي، وتحليـل

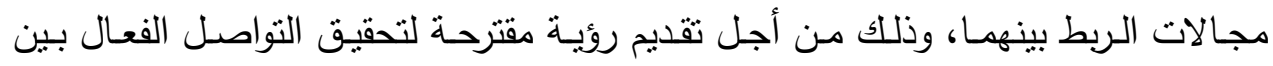
كليات التربية وسوق العمل التربوي.

\section{همخط الدراسسة}

الاراسة وفقًا للمحاور التالية:

المحور الأول: الأطارالنظري للبحث، ويشتمل على البرامج التي تقدمها كلية التربية جامعة بنها، المشكلات المرتبطة بسوق العمل التربوي، مجالات ربط كلية التربية

بسوق العمل التربوي، منطلبات المشاركة بين كليات التربية وسوق العمل التربوي.

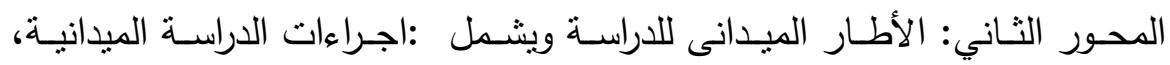

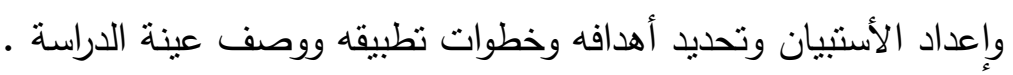

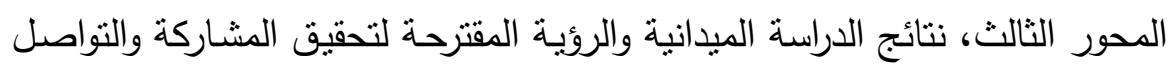
الفعال بين كليات التربية وسوق العمل التربوي.

\section{المهور الأول: الأطار النظري للبحث}

أولاً : البرامج التي تقدمها كلية التربية جامعة بنها :

تقدم كلية التربية جامعة بنها عدد من البرامج على مستوى مرحلة الليسانس والدراسات العليا وبياناتها على النحو التالي :

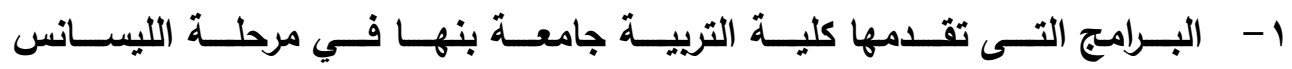

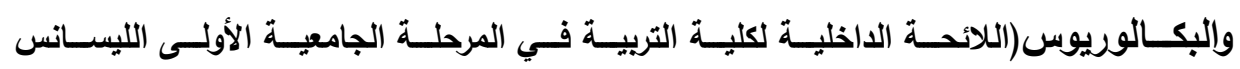
والبكالوريوس، V . . . r):

تقدم كلية التربية جامعة بنها ب ا برنامج:

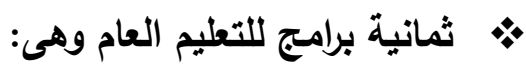
برنامج اللغة العربية والدراسات الإسلامية برنامج اللغة الإنجليزية برنامج التاريخ برنامج الفلسفة والاجتماع 


$$
\text { برنامنامج الرياضيات الفيزياء }
$$

• برنامج العلوم البيولوجية والجيولوجية

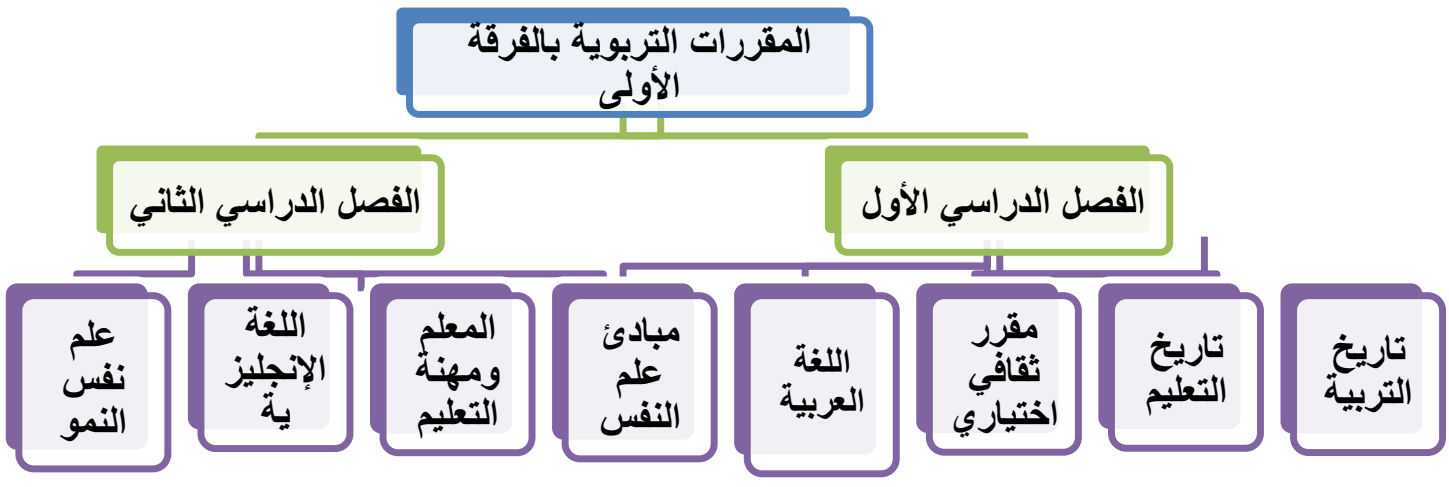

المقررات الدراسية التي يتم تقديمها لبرامج الثعب العامة:

أ- - المقررات التريوية والثقافية:

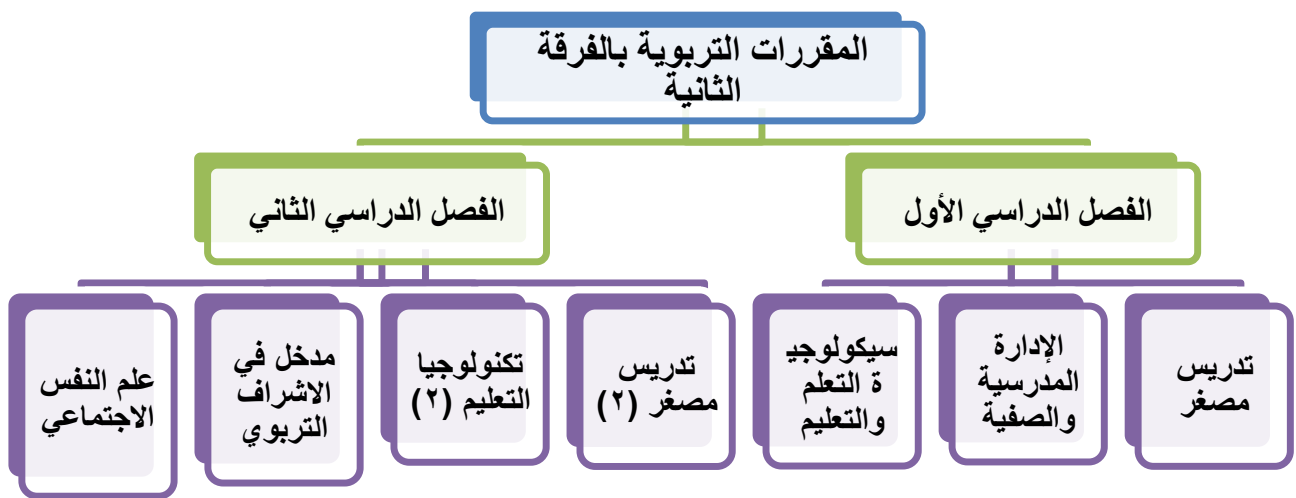



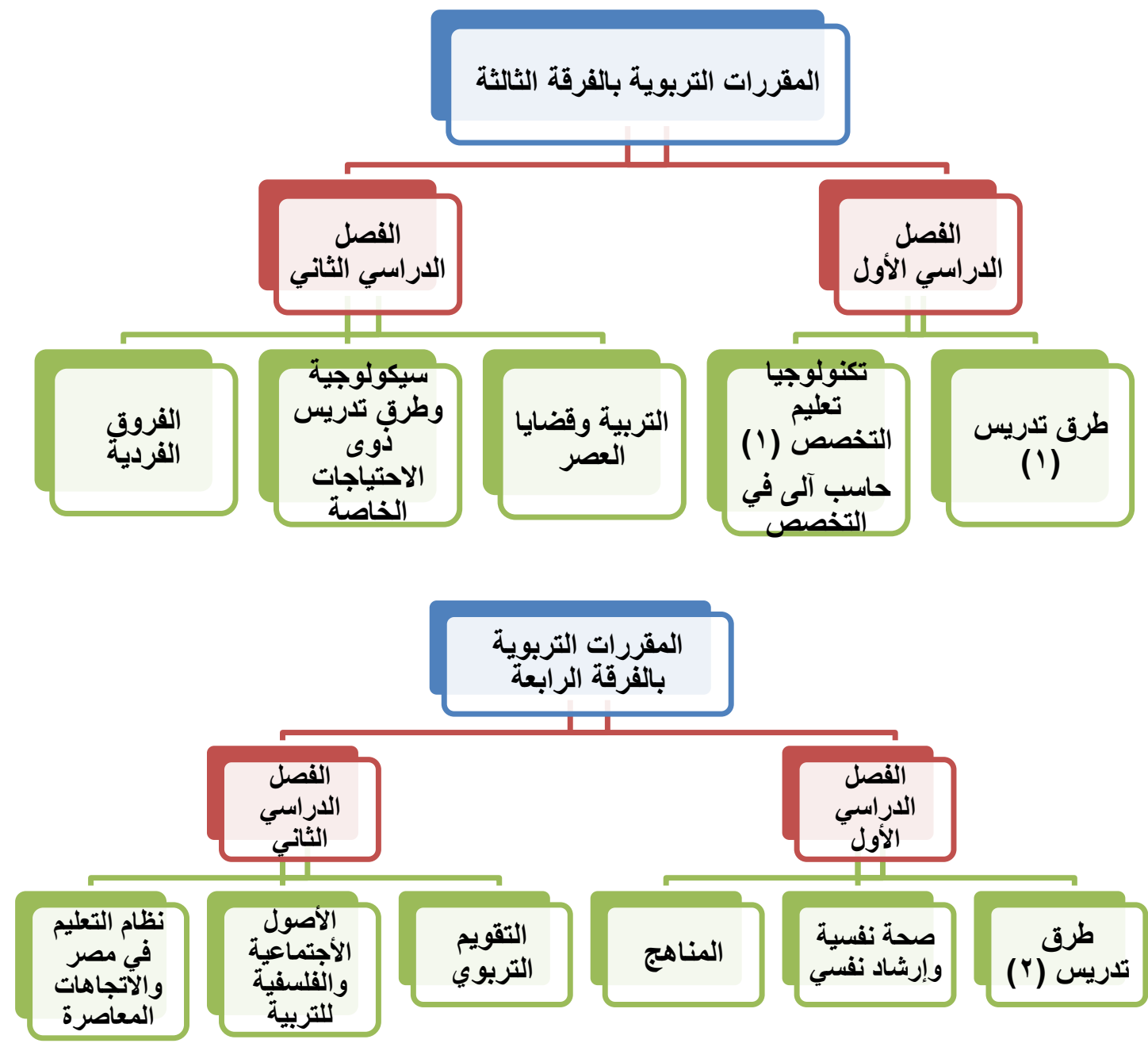

ب- المقررات الثقافية : يختار الطالب مقرراً واحداً من المقرات الثقافية التالية

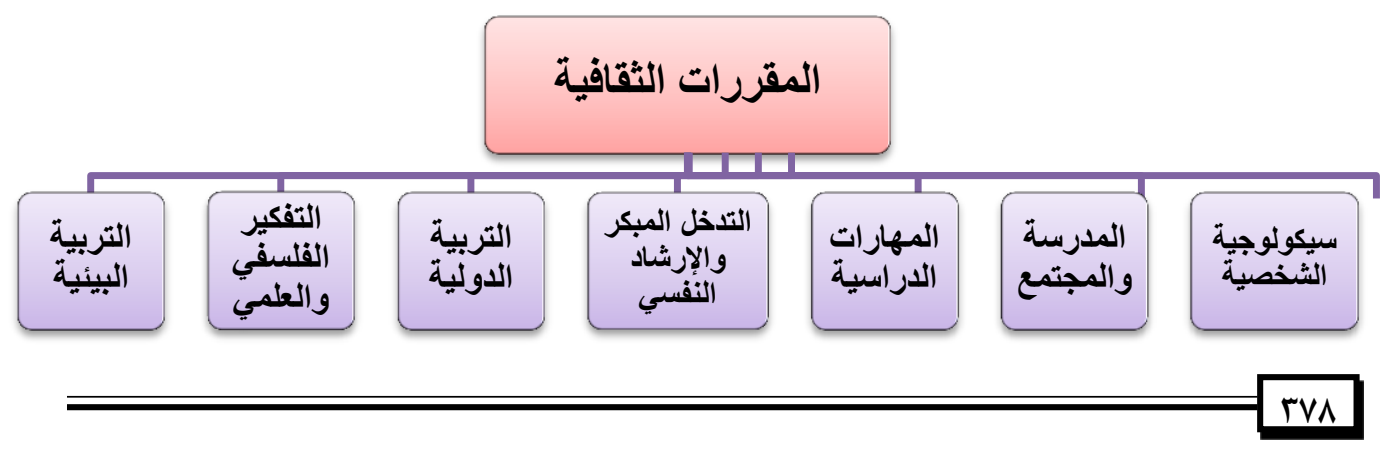




\section{* أربع برامج لشعب التعليم الاساسي وهى:}

برنامج اللغة العربية والدراسات الإسلامية - تعليم اساسي (الحلقة الأولى )

$$
\text { • • برنامج الدراسات الإجتماعية - تعليم اساسي (الحلقة الأولى ) }
$$

r- البرامج التى تقدمها كلية التربية جامعة بنها في مرحلة الدراسات العليا ( اللائحة الداخلية للاراسات العليا بكلية التربية جامعة بنها، ب ا ب ):

تقدم كلية التربية جامعة بنها مجموعة من البرامج خلال في مرحلة الدراسات العليا كالأتي:

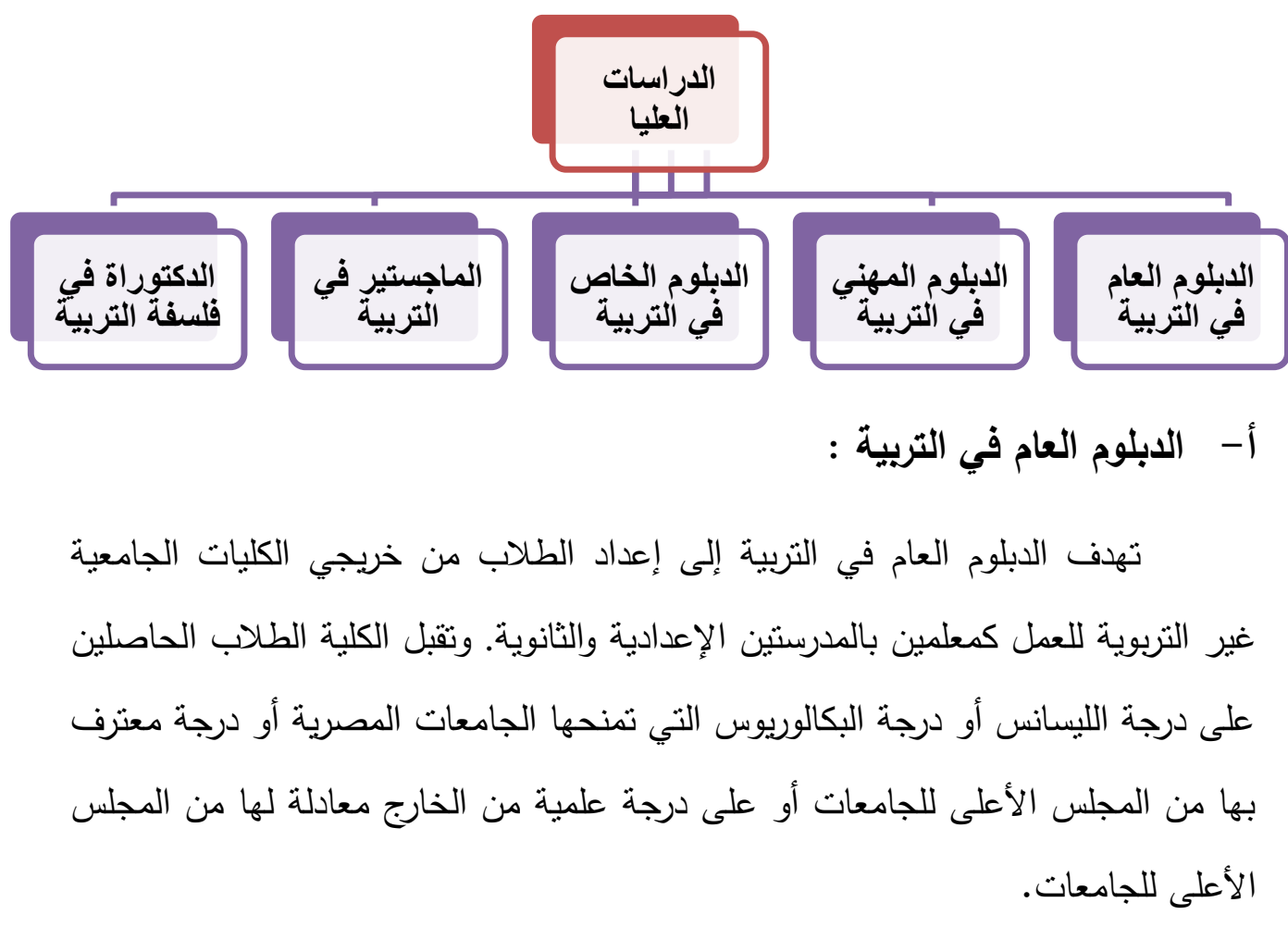


مدة الدارسة للحصول على درجة الدبلوم العام في التربية سنة جامعية للطلاب المتفرغين للارسة ويجوز قبول المعلمين العاملين بمدارس التعليم قبل الجامعي بالدبلوم العام في التربية - مع عدم تفرغهم تفرغا كاملا - ويدرسون في هذه الحالة جميع المقرارت الدارسية

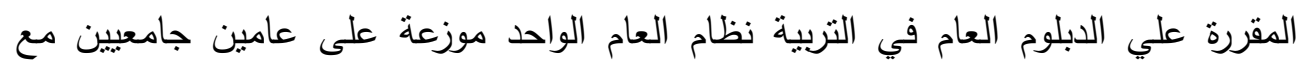
إعفائهم من التدريب الميداني والتدريس المصغر.

\section{البرامج التي يتم تقديمها في الابلوم العامة في التربية :}

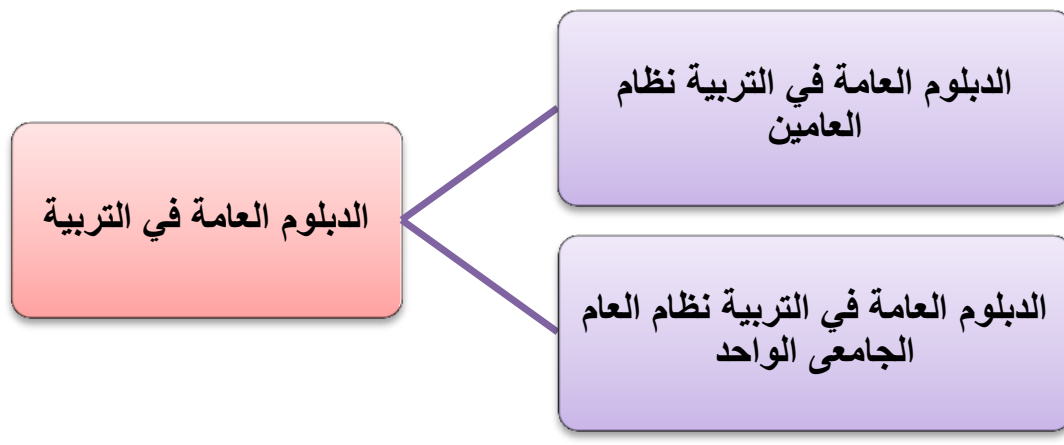

\section{ب- الابلوم المهنية في التربية}

تهدف الدبلوم المهنية إلى إعداد خريجي كليات التربية علميا ومهنيا في تخصص من تخصصات الدبلومات المهنية التي تقدمها الكلية. تقبل كلية التربية بالدبلوم المهنية في التربية الطلاب الحاصلين على درجة الليسانس في الآداب والتربية أو البكالوريوس في العلوم والتربية، أو الدبلوم العامة في التربية من إحدى الجامعات المصرية أو أي مؤهل تربوي جامعي آخر ، أو على درجة علمية أجنبية

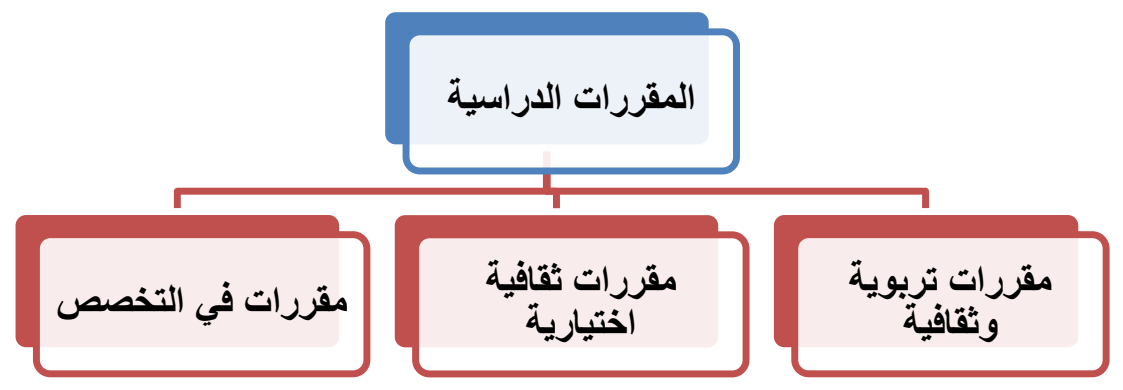


معادلة لأي منها من المجلس الأعلى للجامعات لإعدادهم مهنيا لتخصص الدبلوم المهنية التي يتقدم للالتحاق بها. ويتم قيد الطالب بنظام التعليم النظامي في الدارسة. البرامج التي يتم تقديمها بمرحلة الدبلوم المهنية في التربية :

\section{الابلوم المهني في التربية قسم التربية المقارنة والإدارة}

$$
\text { التعليمية فيمة }
$$

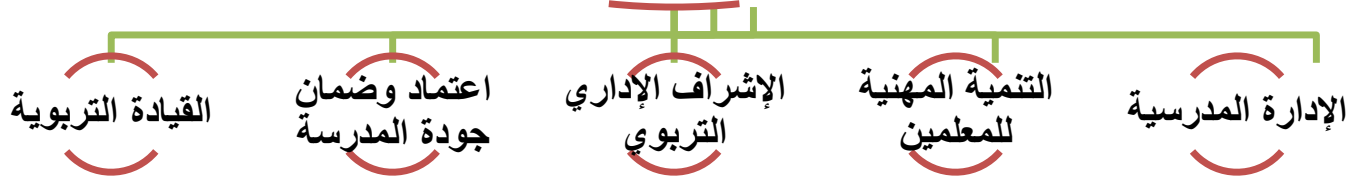

الابلوم المهني في التربية قسم أصول التربية

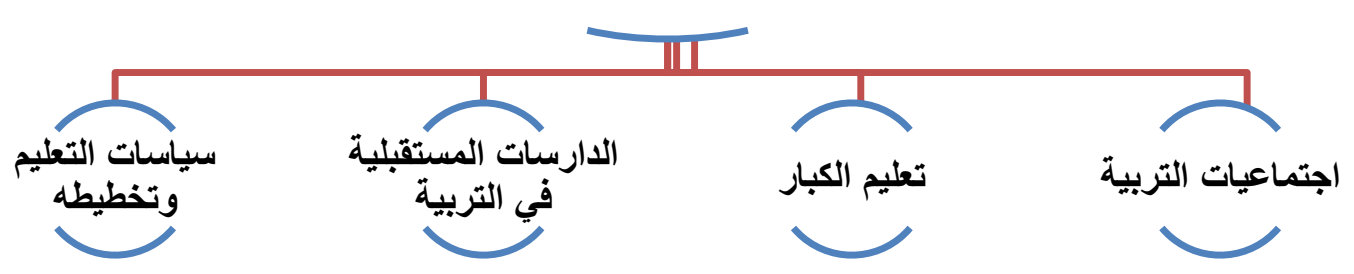

الابلوم المهني في التربية قسم علم النفس التربوي

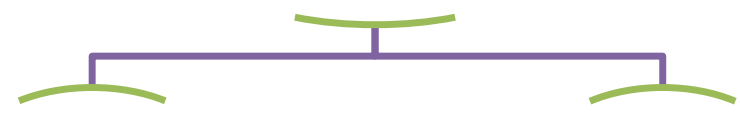

القياس النفسي وتطبيقات الحاسب إعداد الأخصائي النفسي المدرسي 


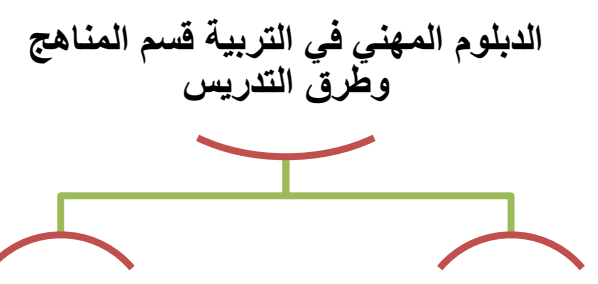

مناهج وبرامج التعليم

تكنولوجيا التعليم

ج- الابلوم الخاصة في التربية :

تهدف الدبلوم الخاصة في التربية إلى إعداد الدارسين وتمكينهم من أساسيات البحث

التربوي في تخصصات القسم التربوي الذي يقيدون به للتسجيل لدرجة الماجستير.

$$
\text { الدبلوم المهني في التربية قسم الصحة }
$$

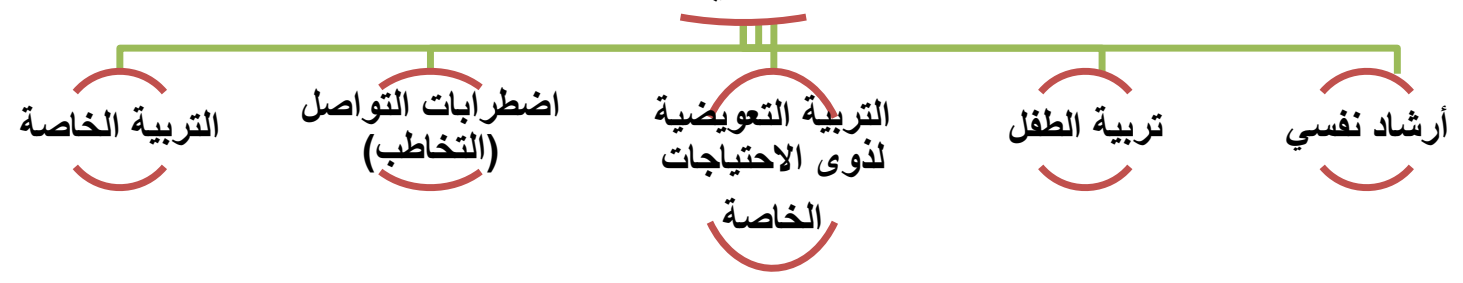




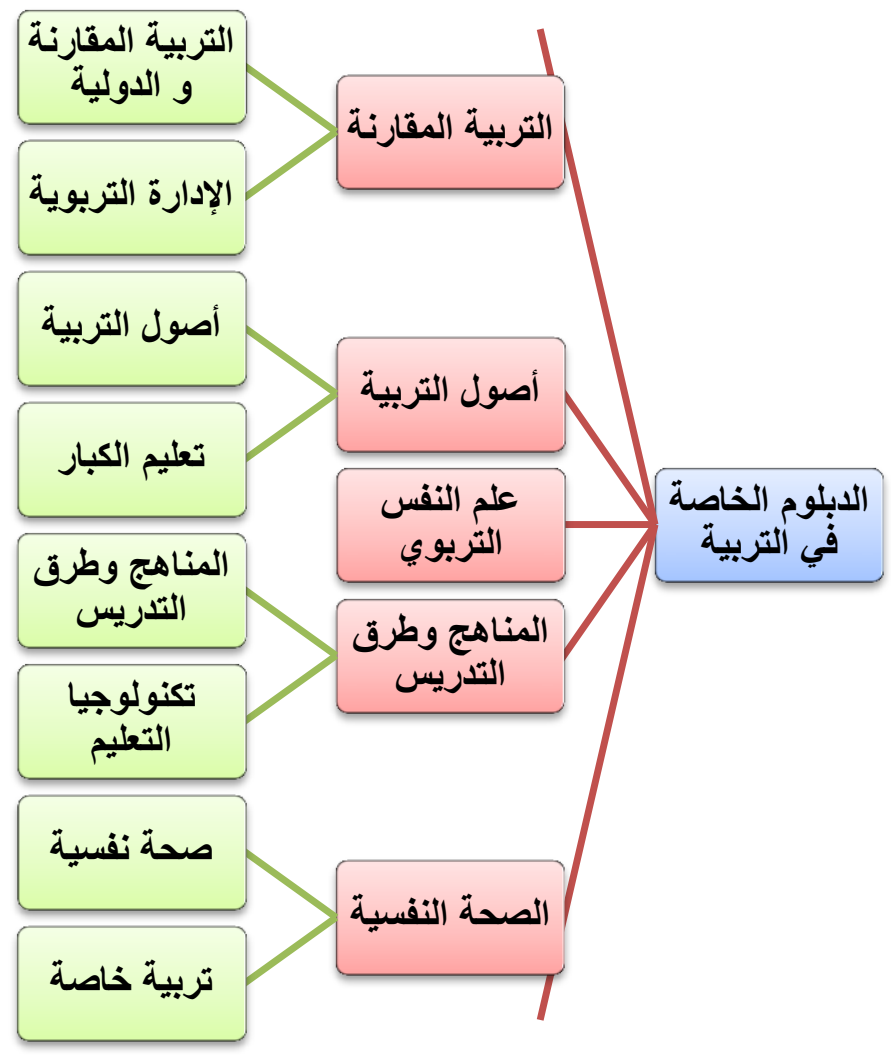

د - الماجستير في التريية : يشترط لقيد الطالب بدرجة الماجستير في التربية مايلي: الحصول على الدبلوم الخاصة في التربية من إحدى الجامعات المصرية بتقدير عام

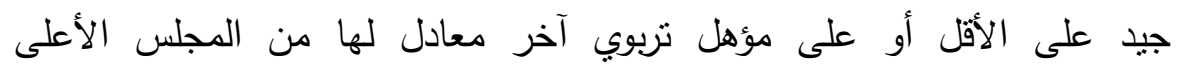
للجامعات.

هأن يكون حاصلا على شهادة التويفل الدولي أو من مركز اللغات بجامعة بنها.

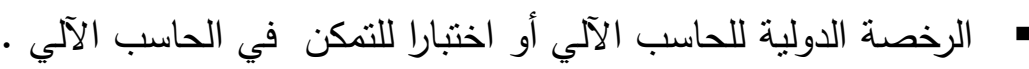

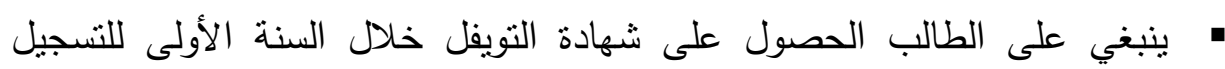

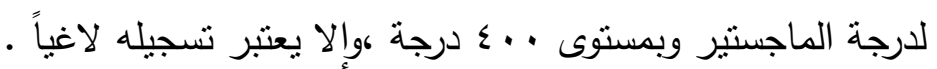




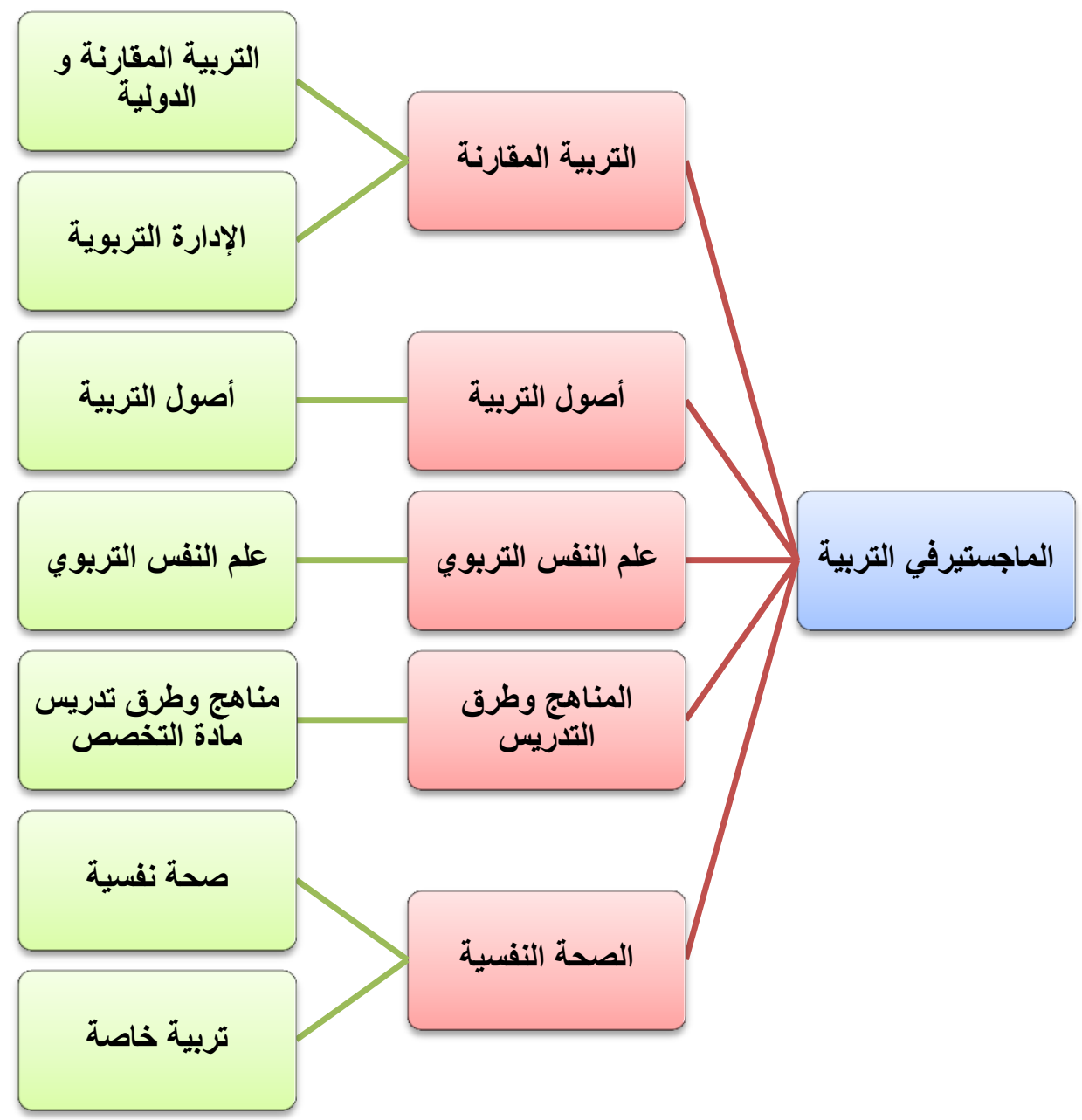

هـ - دكتوراه القلسفة في التربية: يثترط في قيد الطالب لدرجة دكتواره الفلسفة في التربية: ا. أن يكون حاصلا على درجة الماجستير في التربية في شعبة التخصص التربوي من إحدى الجامعات المصرية بتقدير عام جيد على الأقل. r. أن يكون حاصلا على شهادة التوبفل الدولي وفقا لمدة صلاحيتها، وفى حالةتسجيل الطالب لدرجة الدكتواره من جامعة بنها الحاصل منها على شهادة التويفل يعفى من شهادة التويفل. 


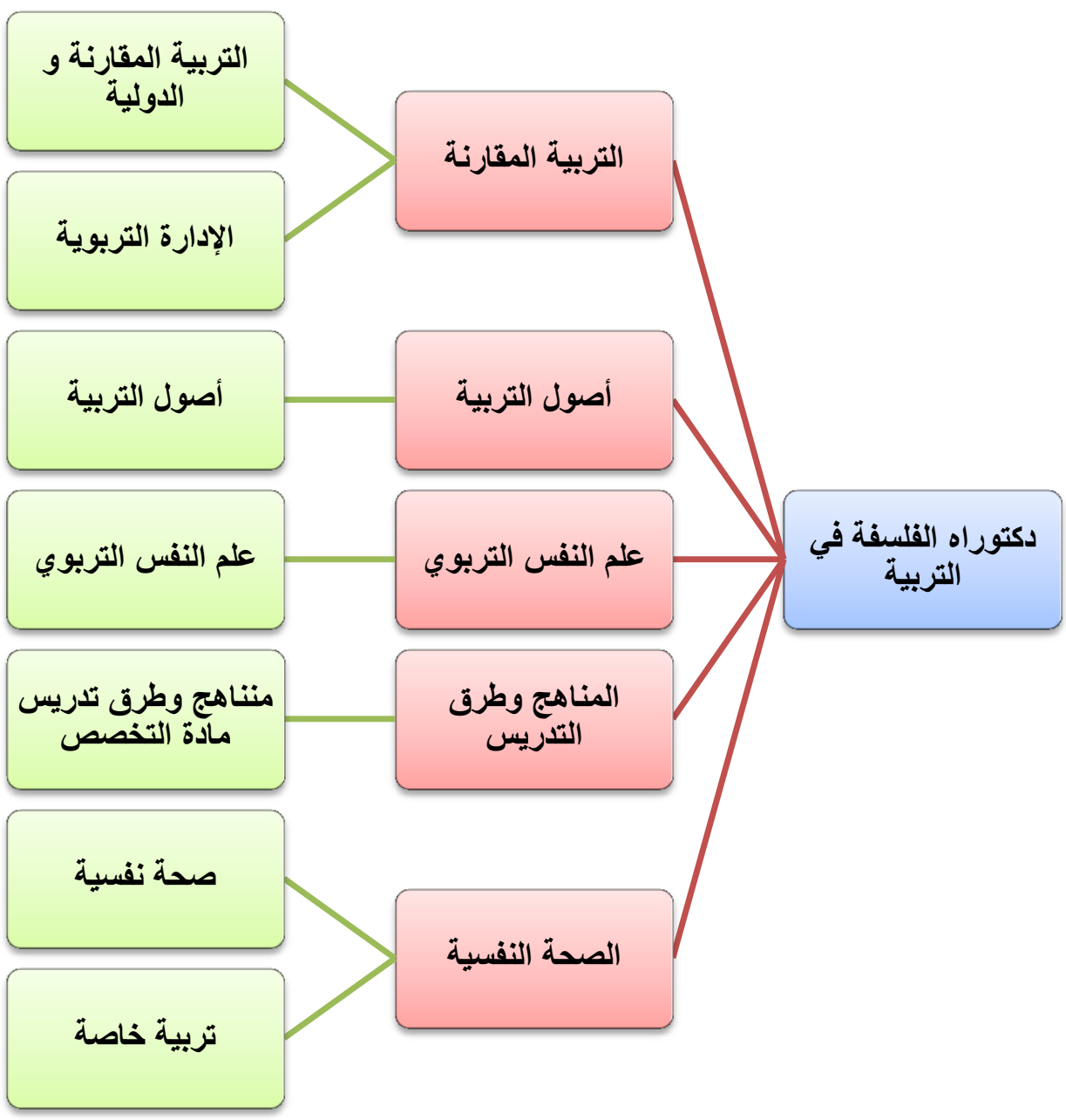

ثانياً : المشكلات المرتبطة بسوق العمل التزبوي :

يمكن تقسيم المشكلات المرتبطة بسوق العمل التربوي بمصر إلي أربع مجموعات رئيسية

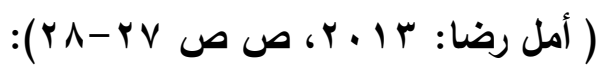
المجموعة الأولي: مشكلة انخفاض الإنتاجية: ويعزي انخفاض الانتاجية إلى العديد من الأسباب: 1. انخفاض مستوي التدريب

r. عدم القدرة علي تطبيق الطرق الانتاجية المنطورة في القطاعات الإنتاجية المختلفة 
r. - الاختلال بين الانتاجية والاجور

ـ. انخفاض المستوي الصحي للعاملين وانتشار العادات غير الصحية المجموعة الثانية: المشكلات المرتبطة بالتأهيل الاكاديمي والمهني والثقافي تتمثل أهم هذه المشكلات في:

ا ـ ارتفاع نسبة الأمية علي المستوي القومي وعلي مستوي قوة العمل؛ مما يؤدي إلي

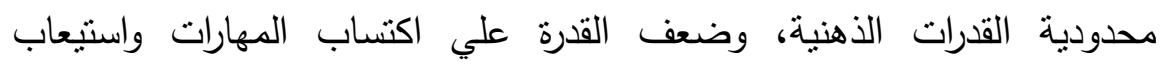
المعارف سواء في التدريب المؤسسي أو أثناء العمل. r. الفجوة الكبيرة بين مخرجات التعليم بكافة مستوياته من ناحية، وبين احتياجات سوق العمل من ناحية أخري. r. عدم مواءمة مهارات الخربجين للعمالة التي يبحث عنها القطاع، وعدم ربط خطة

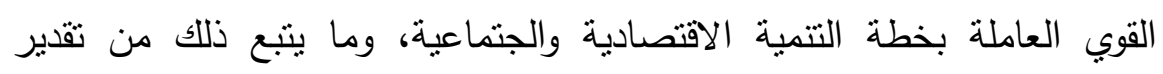
متطلبات الخطة من مختلف المهن والتخصصات،ووجوب توفير صورة واضحة عن النمو الاقتصادي المستهدف في الأجل الطويل علي مستوي القطاعات الإنتاجية المختلفة.

المجموعة الثالثة: التشريعات الحاكمة لسوق العمل لته ترتبط بالقوانين المنظمة للعلاقات خصوصاً تلك التي تضع قيوداً علي خفض التهات مستويات العمالة لديها، اذا ما تطلبت الاعتبارات الاقتصادية للمشروع تغيير حجمه وإدخال أساليب تكنولوجية جديدة مما يؤثز علي نتافسيته.

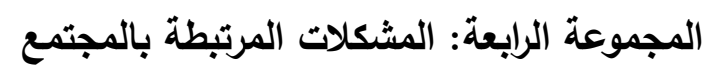
1. النظرة المجتمعية المتدنية للمعلمين r. انخفاض المستوي النقافي والاجتماعي للأسرة والذي يؤدي الي تدني مستوي التحصيل والأداء للأبناء r. اختبار الطلاب للتخصصات تعتمد علي اعتبارات غير موضوعية كتوجية الآباء وعلاوة علي درجاتهم 


\section{ثالثاً : مجالات ربط كلية التربية بسوق العمل :}

تتوعت مجالات الربط بين كلية التربية والأطراف المجتمعية المستقيدين من الخدمة بصفة عامة سوق العمل التربوي خاصة، فمنها ما كان بغرض تقديم الاستشارات، ومنها ما كان بغرض إعداد وتطوير الكوادر البشرية، أو بغرض حل المشكلات أو بغرض البحث والتطوير ، وتجاوزت كلية التربية في علاقتها بالمجتمع للحد الذي أطلق علي هذه العلاقة " علاقة المحور بالمحيط" وهي تلك العلاقة التي تجعل الكلية محوراً لجميع الانشطة التي تقوم بالمشاركة فيها. ومن أهم هذه المجالات: ا ـ مجال إعداد المعلم مهنياً وأكاديميا وثثقافياً: يحتل العظماء مكانة مرموقة في مجتمعاتهم لما يبذلونه من عطاء و تضحية من أجل رفعة أوطانهم وتقدماً، فلم تقتصر قائمة العظماء و المبجلين على الحكام والأدباء المشهورين، بل احتوت على فئات عديدة، ومن هذه الفئات "المعلم" الذي كاد أن يبجل في جميع الثقافات.

فالمعلم يلعب دوراً كبيراً في بناء الحضارات كأحد العوامل المؤثرة في العملية التربوية، إذ يتفاعل معه المتعلم ويكتسب عن طريق هذا التفاعل الخبرات والمعارف والاتجاهات والقيم، لقد شغلت قضية تهيئة المعلم وتأهيله مهنياً، مساحة كبيرة من الاهتمام من قبل أهل التربية، وذللك انطلاقاً من دوره المهم الحيوي في تتفيذ السياسات التعليمية في جميع الفلسفات وعلى وجه الخصوص في الفكر التربوي، فتعد تهيئة المعلم وتأهيله مهنياً من أساسيات تحسين التعليم، وذلك لما لها من أهمية بالغة في تطوير الأداء التدريسي؛ والتتمية المهنية هي مئه

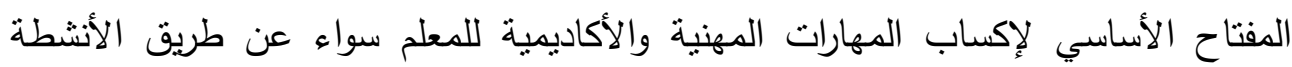
المباشرة في برامج التدريب الرسمية،أو باستخدام أساليب التعلم الذاتي. ونظرا لأن دور المعلم كان ومازال دورا متغيرا مسايراً لمنطلبات النطور الذي يصاحب التعليم كمهنة، تتكاثر اليوم أدوار المعلم على الأقل في أدبيات التربية، حيث يفترض دوران أن

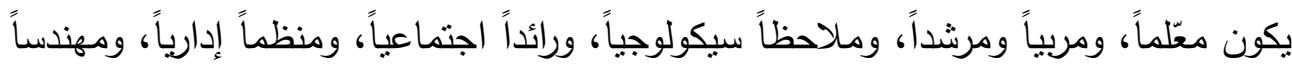
تقنياً ،وباحثًا علمياً، فقد " أصاب دور المعلم نوع من التوظيف التقني في عصر التكنولوجيا 
فائقة التطور، عصر المعلوماتية، والاتصالات الكونية، فالتعليم لم يعد مقصوراً على آليات

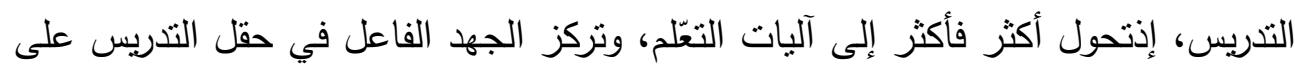

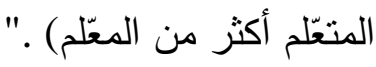
ويمكن تحديد خصائص المعلم القادر على قيادة عملية الإصلاح التربوي والمدرسي فيما يلي

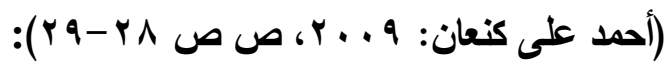

$$
\begin{aligned}
& \text { - يخطط لكل عمل يقوم به. }
\end{aligned}
$$

- التعاطف مع التلاميذ والتجاوب معهم، والصبر عليهم. - - قدرة المعلم على توضيح المواد الدراسية بأسلوب فعال مشوق. - الموضوعية والعدل وعدم التحيز في معاملة التلاميذ. - - الرغبة والحب لمهنة التعليم. - - معرفة المعلم الكافية بأساليب العلوم التي يدرسها والمادة العلمية لها والطرائق

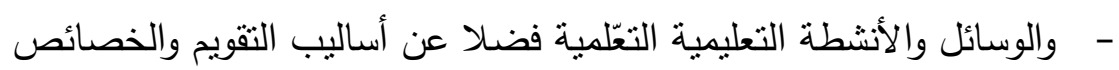
- - معرية للتلامبذ.

- - متحمس ،مرح، يتذوق الفكاهة، أمين، موثوق به، ودود، دمث الخلق.... - - أن يلتزم بقوانين مهنة التعليم ومتطلباتها. - يراعي الفروق الفردية بين التلاميذ ويهيء الفرص للتلاميذ لعرض أفكارهم،

$$
\text { ومشاركاتهم وتغذياتهم الراجعة. }
$$

- - يشترك مع المجتمع المحلي في نشاطاته باستمرار ).

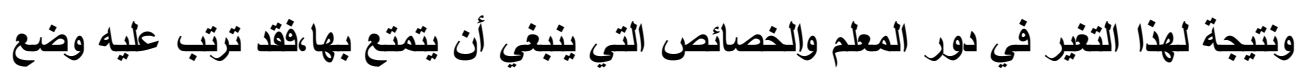

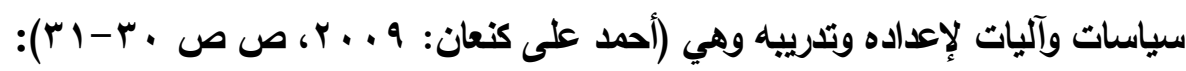
- إعداد مصفوفة الكفايات اللازمة لإعداد المعلم للتمكن من القيام بأدواره التربوية والاجتماعية والقومية والإنسانية.

$$
\text { - - إعداد كل معلمي المدارس في الجامعة. }
$$

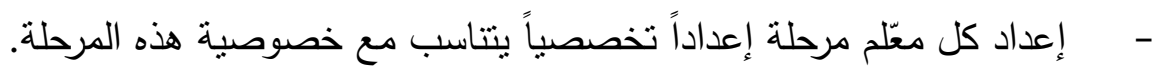
- أن يصبح التدريب المستمر وإعادة التدريب أمرا إلزامياً. 
- - إدخال موضوعات المعلوماتية واستخدام التقانات في مناهج إعداد المدرسين. - تحديد معايير علمية وتربوية وصحية وثقافية ملائمة لانتقاءالمعلمين.

- إنشاء جمعيات ونقابات للمعلمين لرفع مستوياتهم وحل مشاكلهم . " إذاً فإعداد المعلم يجب أن يتم على المستوى الجامعي، بحيث يولي أهمية منوازنة ومتساوية تمكًن المعلم من إجادة المادة أو المواد التي سيقوم بتدريسها وإجادة مهارات التذريس، كما ينبغي أن " يختلف إعداد المعلم حسب المرحلة التي سيقوم بالعمل فيها. المشاركة المجتمعية في وضع وتنفيذ برامج إعداد المعلم : تهتم عدد من الجامعات العالمية بمشاركة جهات من داخل المدرسة وخارجها كالمعلمين وإدارة المدرسة وأولياء الأمور في وضع خطط برامج إعداد المعلم،حيث أصبحت هذه الجهات وخاصة أولياء الأمور عنصر حيوي افي بناء برامج إعداد المعلم وتصميمها، ويرجع إعاءع الاتجاه المطالب بضرورة تبني مبدأ المشاركة في برامج إعدادالمعلم إلى أهميةهذه الجهات وإدراكهم لاحتياجات الطلبة والمجتمع الخارجي كما طالبت العديد من المؤتمرات والدراسات أن تتنفع كليات إعداد المعلم من الخبرات الميدانية للمعلمين لتطوير وتحسين ممارساتها وأنشطتها وبرامجها وتقوم بإجراء التعديلات على برامج الكلية في ضوء احتياجات المعلمين الفعلية في الميدان وفي هذا الصدد يدعو البعض إلى تبني فكرة مدارس النطوير المهني في مدارس حكومية يتم اختيارها بحيث يتم التتسيق بين هذه المدارس والجامعة أو الكلية، وتتم المشاركة معها لتطوير برامج تعليم جيدة لإعداد المعلمين، هذه الفكرة نادت بها مجموعة هي عبارة عن اتحاد لحوالي مائه جامعة في الولايات المتحدة Holmes Group هولمز الأمريكية تتنمل على برامج لإعداد المعلمين. مواكبة المناهج والمقررات للنمو المعرفي المتسارع ، تضمين برامج إعداد المعلمين الكفايات التربوية والتعليمية في ضوء المستجدات التربوية وهذا يتطلب مراجعة دورية للمقررات والمناهج الدراسية ومراجعة الخطط التدريسية في كل قسم من أقسام الجامعة مرة على الأقل كل عامين دراسيين ، وتطوير هذه الخطط بما بطرأ من مستجدات علمية، بحيث تكون هذه الخطط مرنه، وقابلة للتطوير، وليست هره جامدة فما كان يصلح للتدريس قبل خمس سنوات مثنلا، لايمكن أن يظل صالحا إلى ما لا 
نهاية، ومن هنا تأتي ضرورة مراجعة الخطط التدريسية، وملاءمتها مع التطورات العلمية

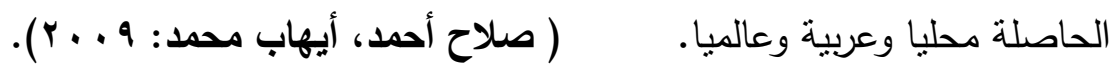
r - مجال برامج التنمية المهنية للمعلم

إن التتمية المهنية للمعلمين تعتبر ضرورة ينطلبها إصلاح شئون التعليم ولعل من أهم

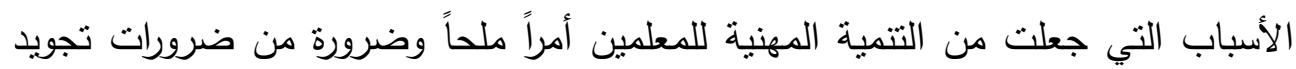
التعليم هي التغيرات والتطورات التي حدثت في البنية المعرفية وتقنيات التعليم وطرائقه المختلفة، إلي جانب تعدد أساليب ونظم العلاقات والأدوار في شتي مناحي العملية التعليمية. وقد أقتضي هذا الأمر ضرورة أن يتعرف المعلم أولاً بأول علي نتائج الدراسات والبحوث في في فئني ميدان التربية والتعليم وكيفية تجريب بعضها في ميدان ممارساته التربوية.

وفي مصر يعتبر التدريب أنتاء الخدمة من أسس تربية المعلمين بعد مرحلة الإعداد.

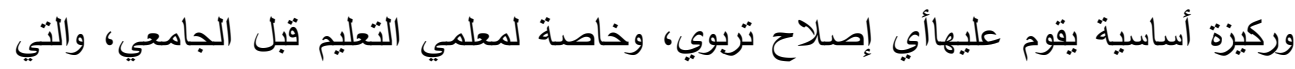
تضم أنماط التعليم العام والخاص والفني في مراحل ما قبل التعليم العالي وهي مراحل الابتدائية والاعدادية والثانوية العامة والفنية والمدارس الثانوية المهنية المتقدمة. وهذا اللون من التعليم يشرف علي كافة فعالياته وأنشطته التربوية والتعليمية وزارة التربية والتعليم والمديريات التعليمية التابعة في مختلف القطاعات.

وتتعدد الجهات التي تتفذ برامج التذريب أثناء الخدمة لهؤلاء المعلمين، ومن هذه الجهات الإدارة العامة للتدريب، والمركز القومي للادتحانات والتقويم التربوي، ومركز تطوير المناهج والمواد التعليمية، والمركز القومي للبحوث التربوية والتتمية، ووحدة التخطيط والمتابعة مع البنك الدولي والاتحاد الأوربي، والإدارة العامة للكمبيوتر التعليمي، إلي جانب مركز التطوير

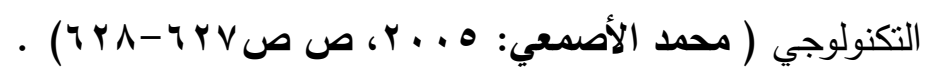

ويعني النمو المهني للمعلم مقدار الزيادة الرغوب فيها من الخبرات المعرفية والانفعالية والمهارية التي يكتسبها المعلم نتيجة التحاقة ببرنامج للتتمية المهنية. وبرامج التتمية المهنية تهتم بعدة مجالات في هذا المحور منها المنهج المدرسي وطرائق التدريس والوسائل التعليمية وتكنولوجيا 
التعليم، ومشكلات الطلاب، وإدارة العملية التعليمية وتتظيمها، إلي جانب مجال العلاقات المهنية

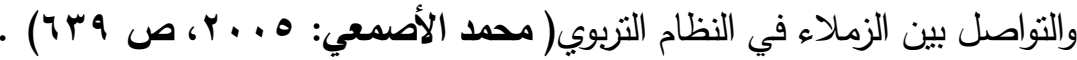
وثمة مشكلات تواجه برامج تدريب المعلمين أثناء الخدمة، والتي والتي تتمركز بصفة عامة في عدم تحديد الاحتياجات التنريبية بصورة دقيقة من البداية، وهذا يؤدي إلي العديد من عمليات الارتجال والعشوائية في عمليات التدريب أثناء الخدمة، ومن ثم تصبح هذه البرامج مضيعة للوقت والجهد والمال، وأيضاً تصبح هذه البرامج شكلية أكثر منها موضوعية. وتتعدد أساليب التتمية المهنية للمعلمين ومنها: أسلوب الإثراف والتوجيه التربوي،

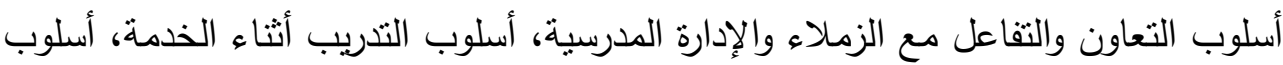

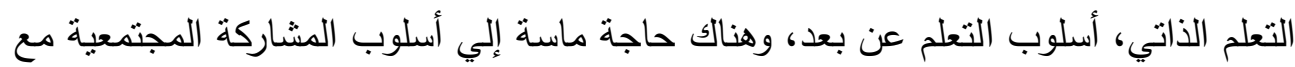
كليات التربية لتحقيق أبعاد التمية المهنية للمعلمين، حيث يستطيع المعلمون الاستفادة من بن الروابط المهنية في المجتمع في نطوير ممارساتهم التعليمية وإثراء خبراتهم التربوية والتدريسية

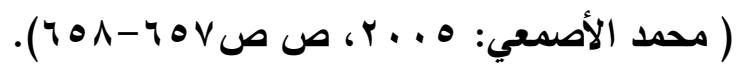

فهناك دعوة لمشاركة مجتمعية فعالة من أجل تجويد التنمية المهنية للمعلمين في النظام

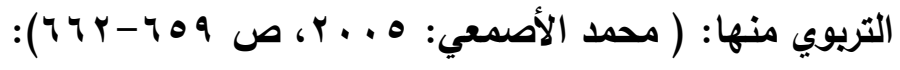

- التفكير في إيجاد نموذج الاستشاري الفني المقيم في المدرسة، بحيث تتحدد مهامه بتدريب المعلمين علي استخدام الكمبيوتر وتتغيله لخدمة البرامج التعليمية المختلفة في

$$
\text { مراحل التعليم قبل الجامعي. }
$$

- - العمل علي إحياء المناقثات المثمرة بين المعلمين حول أفضل الخبرات التدريسية، خاصة مع الطلاب المعلمين أثناء برنامج التربية العملية ومع الخبراء المشرفين عليها مما يثري عملية التتمية المهنية للمعلمين في هذه المدارس. - - إنشاء جماعات المعلمين في كل تخصص دراسي في جميع المدارس التعليم قبل الجامعي، تكون مهنتها الرئيسة تحسين الأداء المهني لأعضاءها وتبني الاساليب التأملية في الممارسات التعليمية للمعلمين. 
- - تحديد الاحتياجات التدريبية بكل دقة للمتدربين من المعلمين، إلي جانب حسن اختيار المعلمين المتدربين والقادة المدربين بما يتتاسب مه هذا التحديد. - - إتاحة الفرصة أمام المعلمين في تبني دورات تدربيية تعقد داخل مدارسهم من وقت

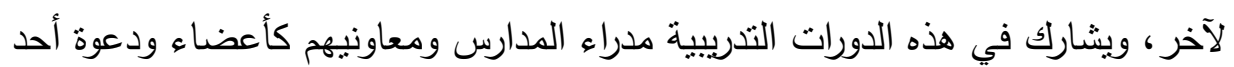
ممثلي كليات التربية بقسم المناهج وطرق التدريس. - التتسيق المستمر بين الإدارات العامة للتدربب بوزارة التربية والتعليم وبين أقسام التنريب بالديريات التعليمية بالمحافظات المختلفة وبين كليات التربية المتواجدة في هذه المحافظات بغرض تحديد أهداف الدورات التدريبية وتتظيمها في الوقت المناسب، والتقكير والتأمل في

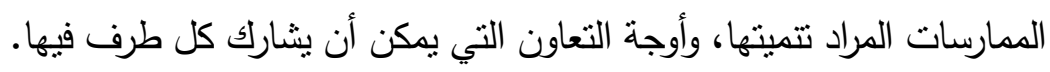

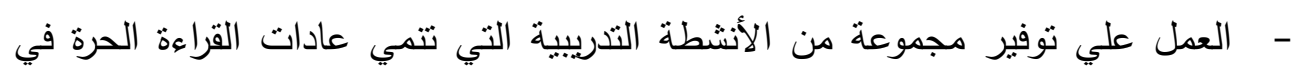
المراجع العلمية والكتب الاضافية، إلي جانب مجموعة من الخبرات يمر بها المعلم

$$
\text { ويمارسها وبتعلم منها وتتمي لديه ما يسمي ( بالذات المهنية للمعلم). }
$$

\section{r. مجال خدمة المجتمع}

تعتبر خدمة المجتمع هي أي نشاط تقوم به الكلية موجة لخدمة أبناء المجتمع من غير

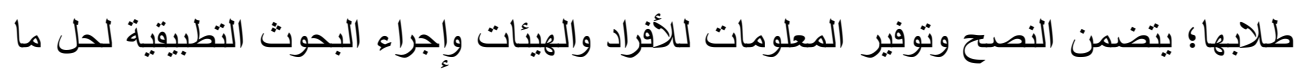
يواجه المجتمع المحلي من مشكلات، وعقد المؤتمرات والندوات واللقاءات وبرامج التدريب للعاملين في أجهزة الدولة ومؤسساتها، ولأبناء المجتمع المحلي عامة. وخدمة المجتمع أيضاً

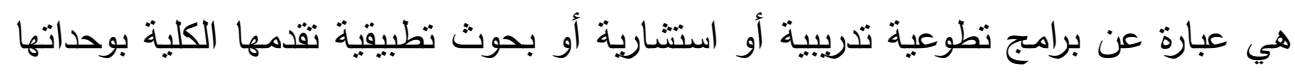

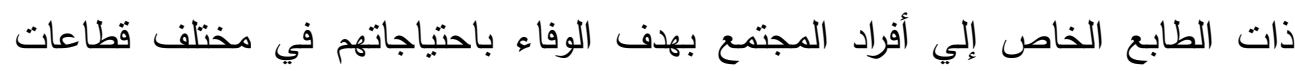

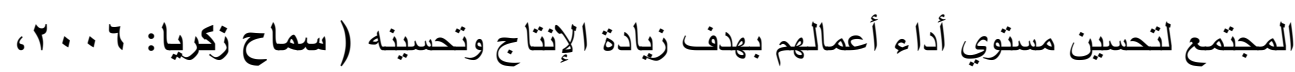

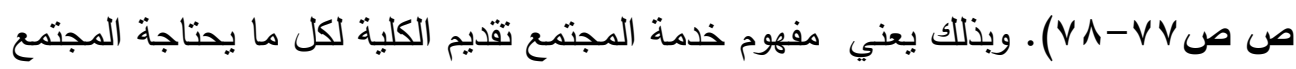
أفراداً ومؤسسات من برامج وأنشطة تعليمية، ومشروعات بحثنية وإنتاجية وتسويقية واستشارات علمية وفنية مستخدمة في ذلك كافة الاككانات المتاحة لديها عن طريق الكوادر العلمية والبحثية ومراكز البحوث والوحدات الخاصة. 


\section{ويمكن تصنيف مجالات خدمة المجتمع التي تقدمها كلية التربية في التالي}

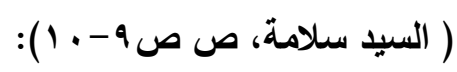

تمتلك كليات التربية من الإمكانات البشربة العلمية ما يجعلها مرشحة للقيام بدور فاعل

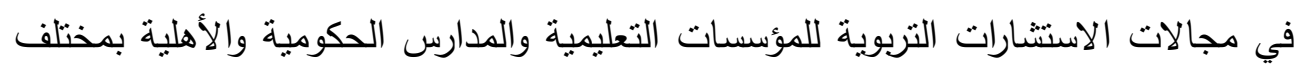
مراحلها.

تتيح المراكز العلمية والخدمية - أهدافاً وتكويناً - القيام بدور فاعل في تتظيم البرامج التذريبية لمختلف العاملين في المجال التعليمي بمختلف مستوياته الإدارية ومراحله التعليمية حيث تقدم برامجها للمعلمين بمختلف مستوياتهم ، وللمشرفين التربوبين ، والفنيين ، التهين والإداريين ، والأخصائيين ، والقيادات التربوية الميدانية والإشرافية.

تسمح البيئة الهيكلية لكليات التربية - ولا سيما في ظل استحداث كثير من المراكز الخدمية والتخصصات الحديثة - بالتوسع في خدماتها للمجتمع لتتجاوز النطاق التعليمي والمدرسي · فبوسع كليات التربية الآن أن تقدم برامج توعوية وتثقيفية وتدريبية للآباء

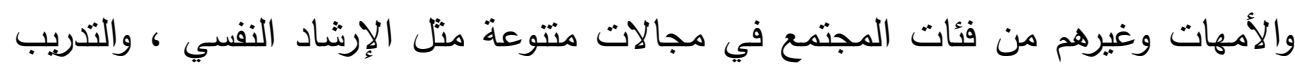
على تقنيات المعلومات ورعاية ذوي الاحتياجات الخاصة ، وتعلم اللغات ، والتربية الأسرية

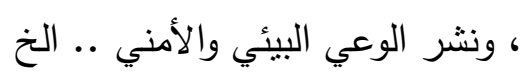

تتيح برامج الإعداد بكليات التربية - ولا سيما في جوانبها الميدانية والتطبيقية - القيام بدور فاعل وميداني في خدمة المجتمع من خلال حملات خدمة المجتمع والبيئة التي تتظمها لطلابها أثتاء الإعداد والتي تكسب الطلاب كفايات خدمة المجتمع حتى يكونوا مؤهلين للقيام بها بعد التخرج.

برامج الإعداد بكليات التربية - سواء كان الإعداد تكامليا أو تتابعيا - تُضّمن أهدافها ورسالتها ما يتعلق بإعداد المعلم لدور اجتماعي وتقافي فعال. فحين تعد كليات التربية - في الإني مجتمعاتتا العربية على سبيل المثال - طلابها للإسهام في محو الأمية وتعليم الكبار في لئي مجتمعه .. أفلا يغني ذلك أنها تؤهلهم لخدمة مجتمعهم والقيام بدور فعال في مواجهة مشكلة اجتماعية وحضارية ملحة .. 
تتتج كليات التربية من خلال أعضاء هيئة التدريس العديد من البحوث والدراسات في مختلف التخصصات ، فنظم الترقي العلمي والمهني تتطلب قيام الأساتذة بإجراء ونشر هن البحوث التي تعالج قضايا علمية وتربوية ملحة ـ هذا النظام يمكن كليات التربية من امتلاك آلية نشطة ومستمرة لتزويد المجتمع بنتائج البحوث والدراسات التي يجريها الأساتذة في لئهن

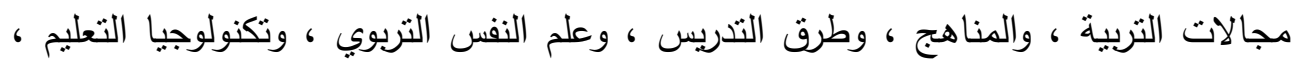
والإدارة التربوبة والمدرسية ، والتربية الخاصة ، والدراسات الإسلامية.

الثروط والمتطلبات التي تمثل ملامح مناخ علمي ومهني مؤهل لقيام الكليات بدورها

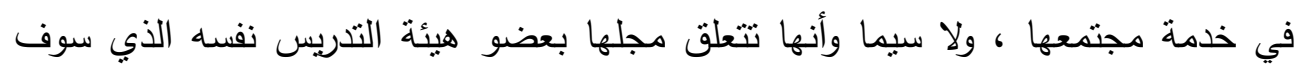

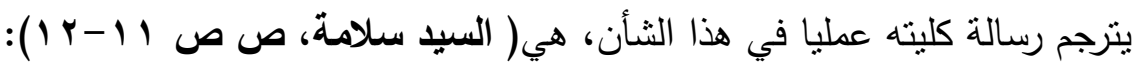
أن تضمن الجامعات وكليات التربية أهدافها صراحة ما يتصل بخدمة المجتمع وتتمية البيئة

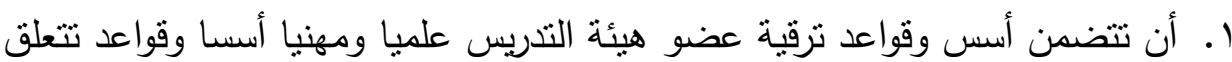

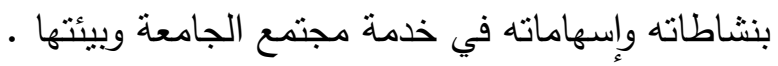
r. أن تعني مراكز خدمة المجتمع بالجامعات والكليات بتسويق خدماتها المجتمعية

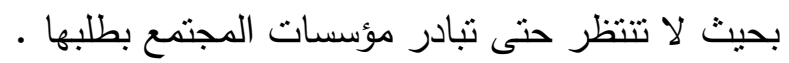

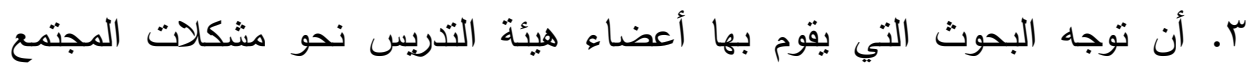
وقضاياه ، بحيث تتضمن البحوث التي يقوم بها أعضاء هيئة التدريس - وعلاوة Applied على البحوث الأساسية التي تعني بالعلم والتراكم العلمي - بحوثاً تطبيقية Action موجهة لخدمة المجتمع او معنية بتقديم حلول لمشكلاته - Research ع. أن يراعى في برنامج إعداد عضو هيئة التدريس علميا ومهنيا إكسابه للكفايات

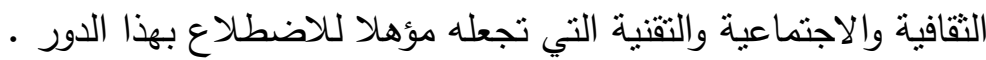
ه. أن توفر الجامعات والكليات برامج تتمية مهنية لعضو هيئة التدريس تتضمن دورات تربوية مستمرة لتتمية كفاياته في خدمة المجتمع وتتمية البيئة . 7. أن يكون هناك من النظم والإجراءات الإدارية والمالية الجامعية ما يساعد على قيام عضو هيئة التدريس بدوره بوعي وفاعلية . 
V. أن تعنى الأقسام العلمية بكليات التربية بالمؤتمرات والندوات وورش العمل والحلقات

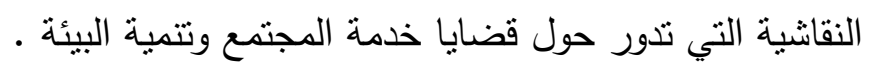

\section{رابعاً : متطلبات المشاركة بيز الكلية والأطراف المجتمعية}

لكي تئدى الكلية دروها بفاعلية اتجاه مجتمعها ، فإن الأمر لا يقتصر على الكلية وحدها إذ لابد من استعداد هذا المجتمع ومؤسساته وهيئاته وكذلك أفراده ... استعدادهم

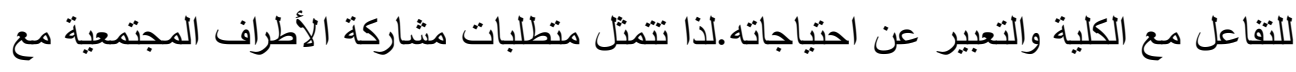
الكلية في:

ا ـ قيام الادارات والأجهزة الإعلامية بالكلية بتبصير المجتمع بمختلف مؤسساته

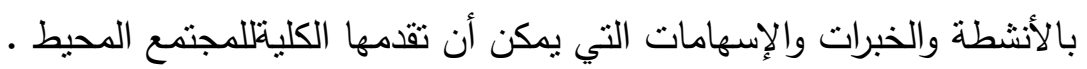
r. اللجوء إلى تعيين أعضاء خارجيين في مجالس الكليات حتى يُسهم هؤلاء الأعضاء بتوثيق العلاقة بين الكلية من ناحية ومؤسسات المجتمع وهيئاته من ناحية أخرى ، ومن ثم ينقلون صورة المجتمع واحتباجاته إلى الكلية .

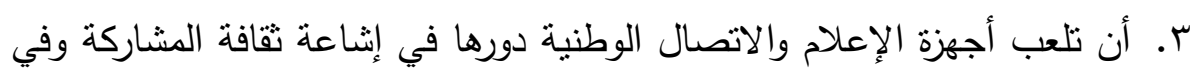

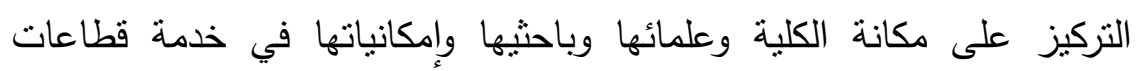
المجتمع المختلفة .

ع. تشجيع القيادات والإدارات العليا بالمؤسسات الإنتاجية والخدمية على اختلاف أنواعها وأنتطتها لحضور المؤتمرات والفعاليات المختلفة بالكلية . ه. استحداث قنوات اتصال جامعية مهيتها التفاعل مع قطاعات المجتمع والترويج للكلية كبيوت خبرة يمكن الاعتماد عليها .

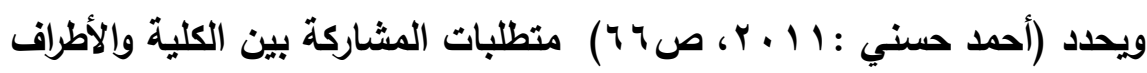

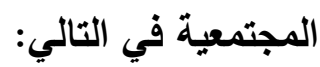
- - تحديد المواصفات المطلوبة - - مشاركة في صنع القرار 
- - الفرصة المتكافئة للتنديب

- - تحديد العائد من المشاركة بالنسبة للطرفين _ - الاعلام والاعلان عما تحقق.

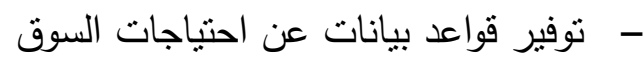

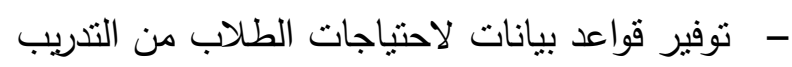
- - توفير بروتوكولات التعاون بين الكلية ومؤسسات المجتمع لئع

\section{المهور الثاني: اجـراءات الدراسة ونتائجها}

يتتاول هذا المحور (اجراءات الدراسة الميدانية وإعداد الاستبيان، وأهداف الاستبيان، وتصميمه ، كما يعرض لتوصيف عينة تطبيق الاستبيان، وخطوات تطبيق الاستبيان، ونتائج تطبيق الاستبيان وتفسيرها.

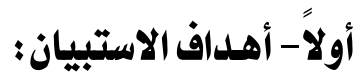
يهرف الاستبيان إلى ما يلي: - - تحديد احتياجات الأطراف المجتمعية من الكلية. - - التعرف على مستوى رضا الأطراف المجتمعية فيما تقدمه الكلية من خدمات. - - مضع مقترحات لتحقيق التواصل الفعال بين الكلية والمستقيدين من الخدمة. ثانياً - تصميـم الاستبيان : 1- إعداد الصورة المبدئية للاستبيان:

نم صباغة هذه الصورة الأولية للاستنيان بالاستعانة بالمصادر التالية.

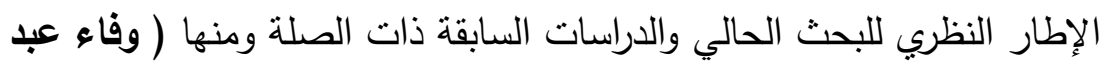

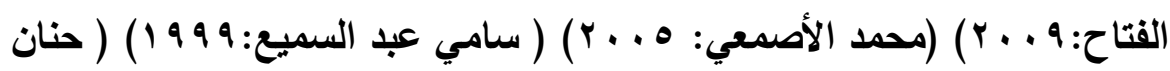

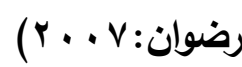
ويتكون الاستبيان في صورته المبدئية من أربع محاور رئيسية كالأتي:

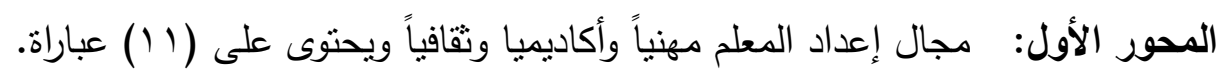
المحور الثاني: مجال برامج التتمية المهنية للمعلم ويحتوى على (Y I ) عباراة. 
المحور الثالث: مجال خدمة المجتمع ويحتوى على (V) عبارات.

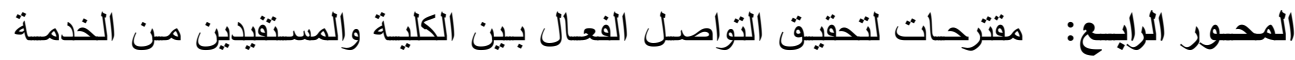

$$
\text { ويحتوى على (^) عبارات. }
$$

تم صياغة المحاور الاربعة للاسنيان في شكل عبارات مقيدة بوضع المستجيب علامـة ( ل) أمام درجة الرضا أو الموافقة وذلك من ثلاث درجات معطاة (كبيرة- منوسطة- - لا).

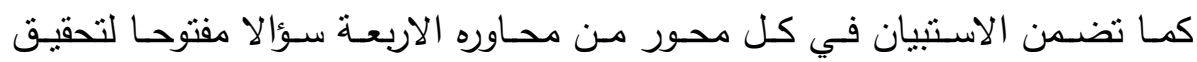
الاستجابات الحرة غير المقيدة لأفراد العينة.

وتم عرض الاستنيانة في صسورته المبدئيسة على عدد مـن المحكمين (ملحق (1)

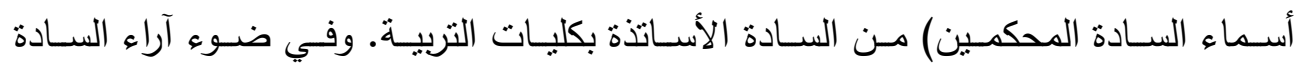
المحكمين تمت الصياغة النهائية للاستبيان.

\section{r- الصورة النهائية للاستبيان}

وعلى ضوء ما طرأ من تعديلات وحذف وإضافة وإعادة صياغة بعض المفردات بحيث تكون مفهومة وواضحة وفي ضوء نتائج تحكيم الاستبيان. أخذ الاستبيان صورته النهائية (ملحق (Y) الاسنيبان فى صورته النهائية،) كما يلي:

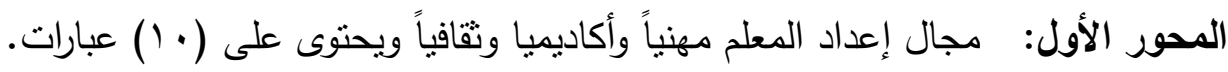

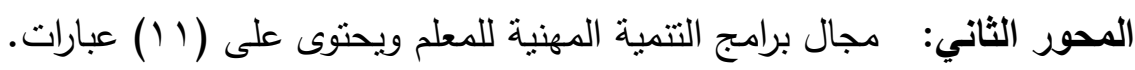
المحور الثالث: مجال خدمة المجتمع ويحتوى على (؟) عبارات. المحور الرابع: مقترحات لتحقيق التواصل الفعال بين الكلية والمستفيدين من الخدمة

$$
\text { ويحتوى على (V) عبارات. }
$$

تم صياغة المحاور الاربعة للاستبيان في شكل عبارات مقيدة بوضـع المستجيب

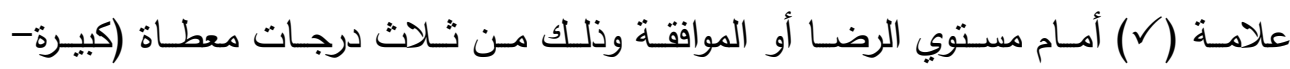
منوسطة- - ضعيف). كمـا تضــن الاسـتبيان في كـل محسور مـن محساوره الاربعـة سـؤالا مفتوحـا لتحقيـق الاستجابات الحرة غير المقيدة لأفراد العينة. 
ثالثاً- عينة الدراسة: تم اختيار عينة الدراسة من المؤسسات التربوية في مجتمع القليوبية وبياناتها كالآتي:

جدول (1) توزيع أعداد العينة المختارة من المؤسسسات التربويتة

\begin{tabular}{|c|c|c|}
\hline ملاحظات & 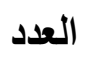 & اسم المؤسسة \\
\hline \multirow[t]{3}{*}{ ( مديروا الإدارات + الموجهون) } & or & مديرية التربية والتعليم وادارتها التعليمية \\
\hline & $\varepsilon$ & الأكاديمية المهنية للمعلمين \\
\hline & $\varepsilon$ & الهيئة العامة لتعليم الكبار \\
\hline \multirow[t]{3}{*}{ معلموا المواد المختلفة } & $\leqslant \varepsilon$ & المدارس الحكومية ( المعلمون ) \\
\hline & 7 & المدارس الخاصة ( أصحاب المدارس) \\
\hline & 11. & الإجمالي \\
\hline
\end{tabular}

وقد تم اختيار العينة في ضوء الضوابط الآتية:

ا. اختيار المدارس من مناطق مختلفة لتمثل المجتمع التربوي بالقليوبية تمثيلا مناسبا وهذه المدارس من مدينة بنها وبعض القري المحيطة بها ومدينة طوخ وبعض القري

المحيطة بها ومدينة قليوب وبعض القري المحيطة بها.

r. اختيار عينة من معلمي المواد المختلفة ( اللغة العربية ، الإتجليزية، العلوم، والرياضيات، والدراسات الاجنماعية، والفلسفة) إضافة الى الأخصائي النفسي والاجنماعي. r. تمثيل موجهي معظم المواد الدراسية في عينة الدراسة. ـ. تمثيـل معظم رؤسـاء الأقسـام بمديريـة التربيـة والتعليم بالقليوبيـة ، والإدارات المختلفـة ادارة التعليم الابتدائي، والتعليم الإعدادي، والتعليم الثانوي، وتمثيل مدير الأكاديميـة المهنية للمعلمين فره القليوبية، ومدير الهيئة العامة لتعليم الكبار فرع القليوبية.

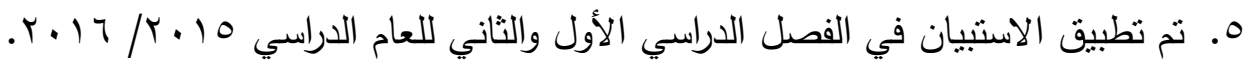




\section{نتائج الدراسة}

1- النتائج المتعلقة بالتحليل الكمي للاستبيان:

تم حساب التكرار والنسبة المئوية للتكرار والقيمة التقديرة لكل مفردة من مفردات الاستنيان، وترتيب هذه المفردات وفقا للقيمة التقديرية لكل منها وذللك بالنسبة للمدراء في هنيه مديرية التربية والتعليم والأكاديمية المهنية والهيئة العامة لتعليم الكبار والموجهين والمعلمين ولئن

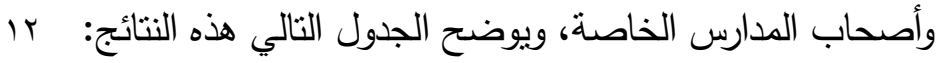

جدول (r) نتائج التحليل الكمي لرضا الأطر اف المجتمعية وتحديد احتياجاتهم من الكليته

\begin{tabular}{|c|c|c|c|c|c|c|c|c|c|c|}
\hline & \multicolumn{8}{|c|}{ درجــــــالـرضــــــا } & \multirow{3}{*}{ 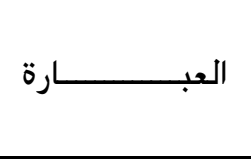 } & م \\
\hline \multirow{3}{*}{ 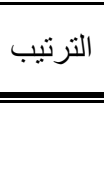 } & القيمة & & \multicolumn{2}{|c|}{ ע } & \multicolumn{2}{|c|}{ متوسطت } & \multicolumn{2}{|c|}{ كبيرة } & & \\
\hline & التقديرية & الهي & $\%$ & ك5 & $\%$ & ك & $\%$ & ك & & \\
\hline & \multicolumn{10}{|c|}{ أولاً: مجال إعداد المعلم مهنياً وتخصيصياً وثُقافياً: } \\
\hline$\varepsilon$ & $r . \Sigma V T$ & TVY & ro. & rی & 1.1 & r & VY.VT & ᄉ. & 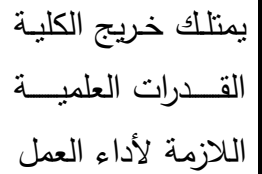 & 1 \\
\hline r & r.ONT & rA乏 &. .17 & 11 & $\ldots 9$ & 1 . & $V \leqslant .00$ & Nr & 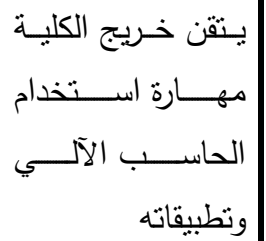 & r \\
\hline 1 & 5.091 & r 10 & $\ldots 9$ & 1. & . & ro & $7 \curlywedge .1 \Lambda$ & vo & 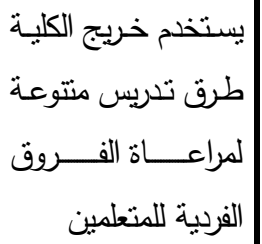 & $r$ \\
\hline$\wedge$ & $r .99$ & r. & דז. & $\varepsilon$. &. .11 & r. & $\leq 0 . \leqslant 0$ & 0 . & 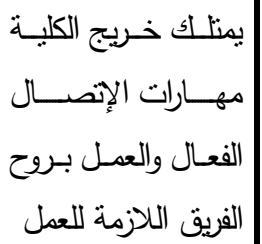 & $\varepsilon$ \\
\hline
\end{tabular}




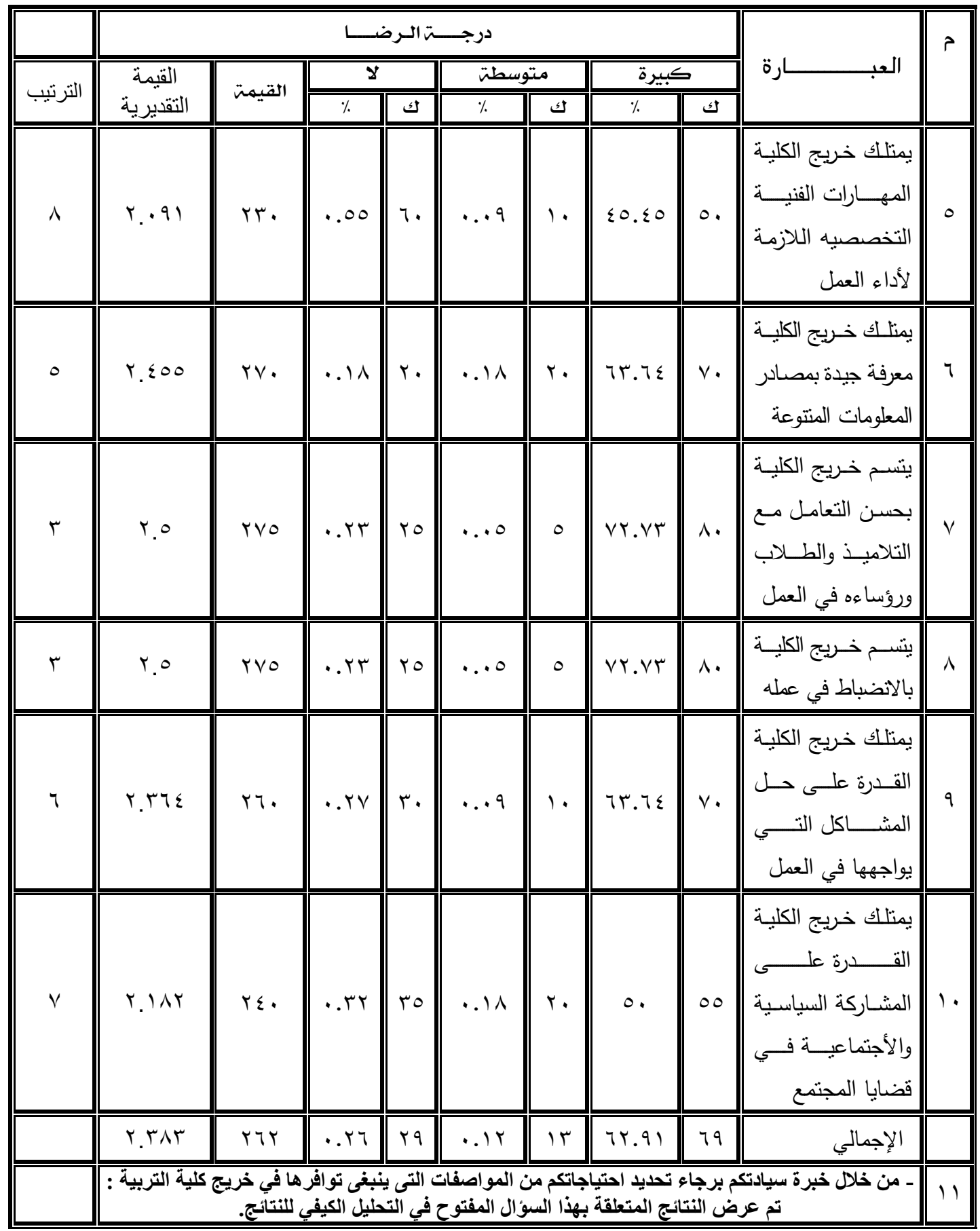


دراسة تحليلية لاحتياجات سوق العملا ورضا

الأطرافـ المجتمعية عن خريجيي كلية التربية
فريق الشاركة المجتمعية

بوحدة ضمان الجودة بالكلية

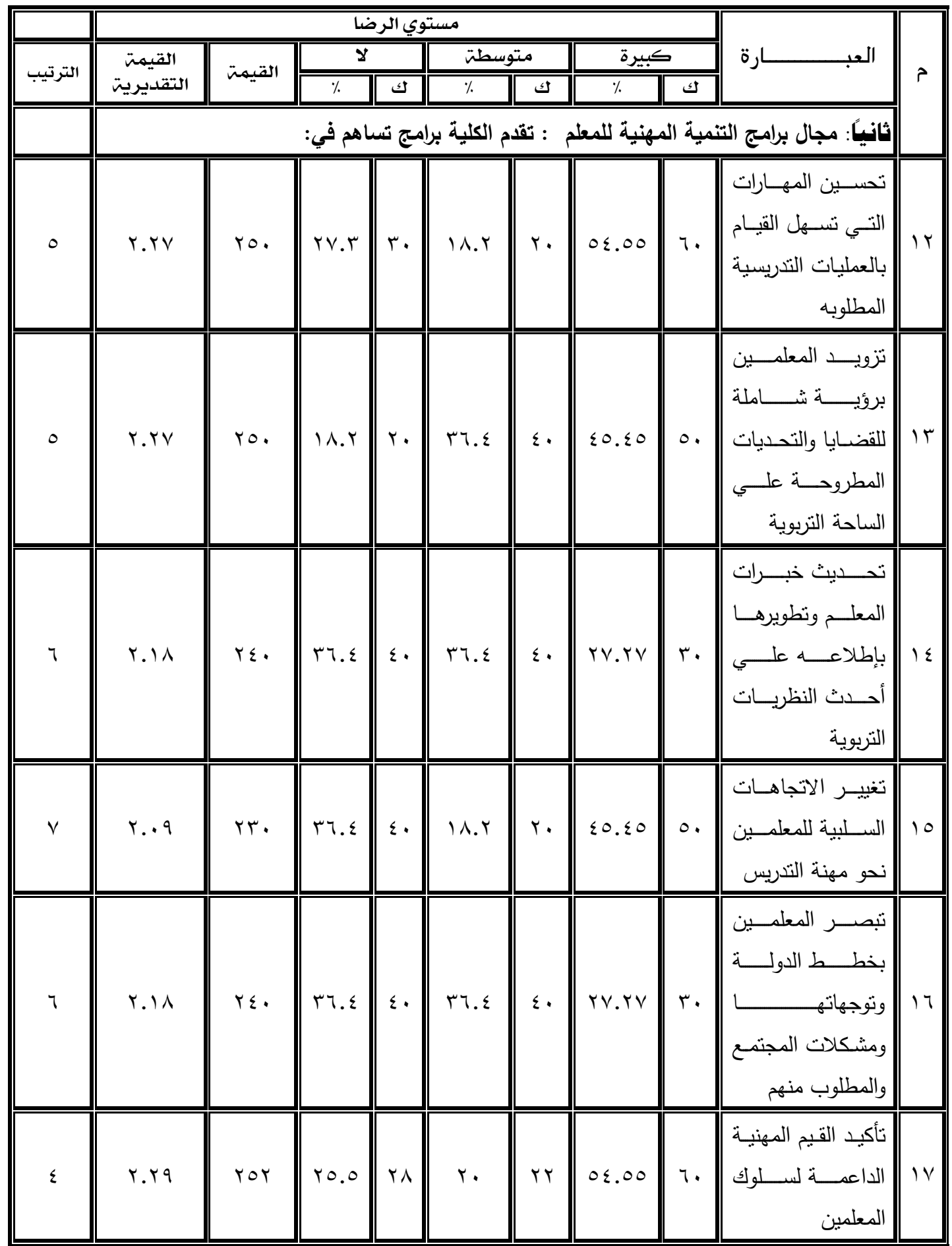




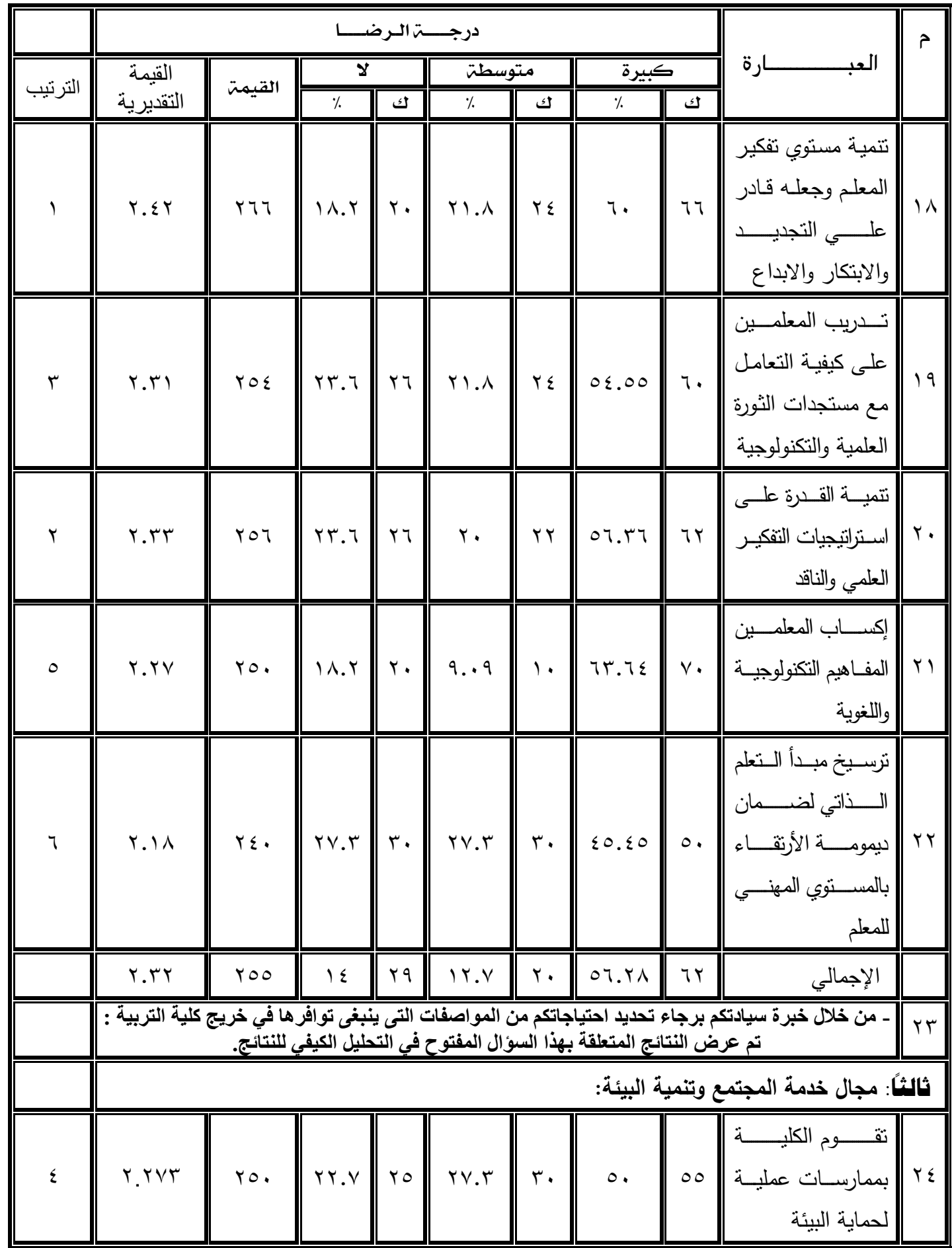


دراسة تحليلية لاحتياجات سوق العملا ورضا

الأطراف المجتمعية عن خريجيي كلية التربية
فريق الشاركة المجتمعية

بوحدة ضمان الجودة بالكلية

\begin{tabular}{|c|c|c|c|c|c|c|c|c|c|c|}
\hline$r$ & r. 0 & TVO & $9 . .9$ & 1. & r.. & ro & $09 . .9$ & 70 & 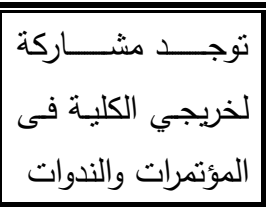 & ro \\
\hline r & T.rTV & rot & ro.o & rA & TV.r & $r$. & $0 . .91$ & 07 & 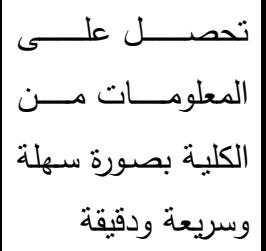 & $r 4$ \\
\hline 1 & r. $0 \leq 0$ & rA. & $11 . r$ & $r$. & $9 . .9$ & 1. & VY.VT & $\wedge$. & 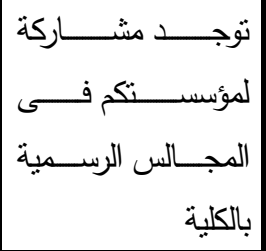 & TV \\
\hline 0 & $1 . \wedge 11$ & $r .$. & $0 \leqslant .0$ & 7. & $9 . .9$ & 1. & דוז.r & $\varepsilon$. & 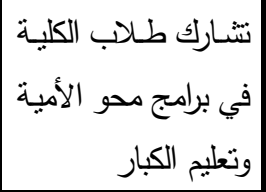 & $r \wedge$ \\
\hline 7 & $1 . V Y V$ & 19. & $0 \leqslant .0$ & 7. & $1 \Lambda . r$ & r. & TV.TV & $r$. & 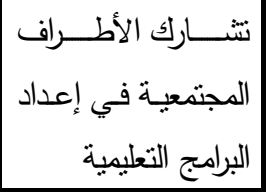 & $r q$ \\
\hline & r.rq & ror & IV.V & $r$. & $1 \leqslant . \varepsilon$ & r & $0 \leqslant . \vee 0$ & 7. & الإجمالي & \\
\hline & \multicolumn{10}{|c|}{ 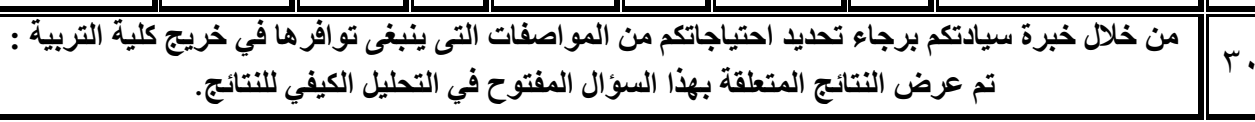 } \\
\hline & \multicolumn{10}{|c|}{ رابعًا: مقترحات لتحقيق التواصل الفعال بين الكلية والمستفيلين من الخدمة: } \\
\hline 0 & $r . \wedge 1 \wedge$ & r. & & & $1 \Lambda . r$ & r. & NI.Ar & 9. & 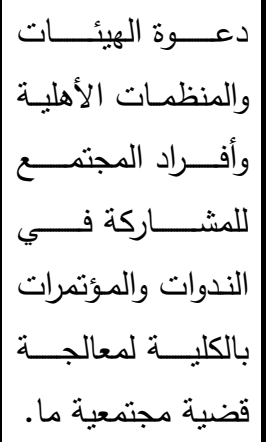 & 1 \\
\hline
\end{tabular}




\begin{tabular}{|c|c|c|c|c|c|c|c|c|c|c|}
\hline & \multicolumn{8}{|c|}{ درجـــــت الـرضــــــا } & \multirow{3}{*}{ 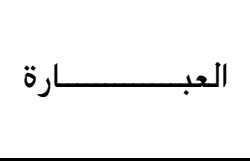 } & \multirow[t]{3}{*}{ a } \\
\hline \multirow{2}{*}{ الترتيب } & \multirow{2}{*}{ التقديرية القيمة } & \multirow{2}{*}{ القيمت } & \multicolumn{2}{|c|}{$y$} & \multicolumn{2}{|c|}{ متتوسطت } & \multicolumn{2}{|c|}{ كبيرة } & & \\
\hline & & & $\%$ & ك5 & $\%$ & ك & $\%$ & ك5 & & \\
\hline 1 & $r$ & . & & & - & - & $1 \cdots$ & 11. & 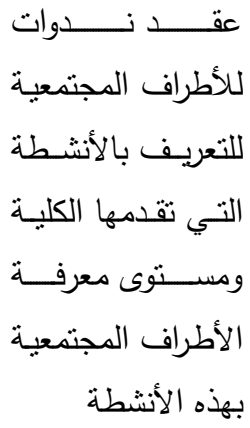 & r \\
\hline 0 & $r . \wedge 1 \wedge$ & W. & & & $1 \wedge . Y$ & $r$. & AI.Ar & 9. & 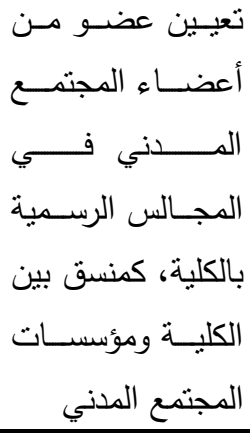 & r \\
\hline$r$ & $r .9 r V$ & Trt & & & $V . r V$ & $\wedge$ & qT.VT & $1 \cdot r$ & 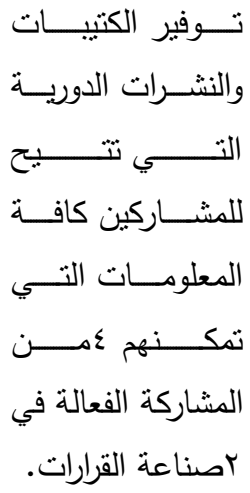 & $\varepsilon$ \\
\hline
\end{tabular}


دراسة تحليلية لاحتياجات سوق العملا ورضا

الأطراف المجتمعية عن خريجي كلية التربية
فريق الشاركة المجتمعية

بوحدة ضمان الجودة بالكلية

\begin{tabular}{|c|c|c|c|c|c|c|c|c|c|c|}
\hline & \multicolumn{8}{|c|}{ درجــــت الـرضـــــا } & \multirow{3}{*}{ العبــــــــــــارة } & \multirow{3}{*}{ م } \\
\hline \multirow{2}{*}{ الترتيب } & \multirow{2}{*}{\begin{tabular}{c|} 
التقديرية \\
\end{tabular}} & \multirow{2}{*}{ القيمت } & \multicolumn{2}{|c|}{ ע } & \multicolumn{2}{|c|}{ متوسطت } & \multicolumn{2}{|c|}{ كبيرة } & & \\
\hline & & & $\%$ & ك5 & $\%$ & ك & $\%$ & ك & & \\
\hline$\varepsilon$ & r.9.9 & r. & & & $9 . .9$ & 1. & $9 . .91$ & $1 \cdots$ & 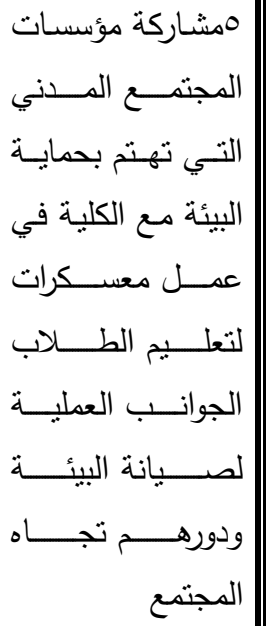 & ० \\
\hline r & r.900 & Tro & & & $£ .00$ & 0 & $90 . \leqslant 0$ & 1.0 & 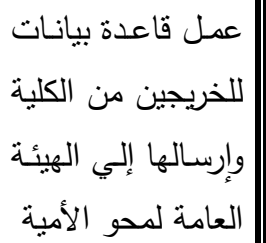 & 1 \\
\hline 0 & r.A1^ & r. & & & $11 . r$ & $r$. & NI.Ar & 9. & 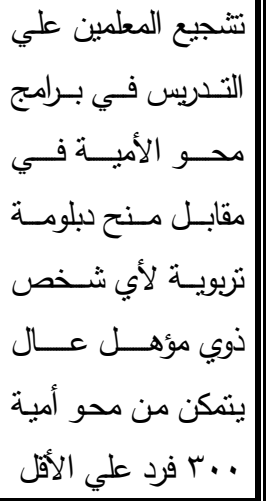 & v \\
\hline & r. 197 & $r \leqslant r$ & & & IT.V & 19 & $71.7 \varepsilon$ & 71 & & \\
\hline & & 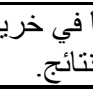 & & & & & & مَ برد & ـ ـ من خلال خبرة سياد & $\wedge$ \\
\hline
\end{tabular}

من خلال جدول ( r r ) والأي يوضح النتائج الكمية للاراسة يتضح الآتي: 


\section{أولاً: مجال إعداد المعلم مهنياً وتخصيصياً وثُقافياً:}

يركز هذا المحور على مستوي رضا الأطراف المجتمعية وتحديد احتياجاتهم من

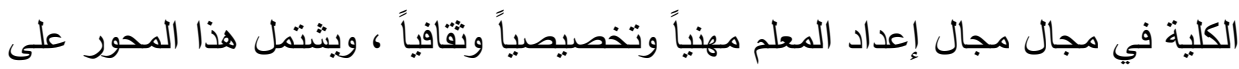

$$
\text { ( • ( ) عبارات وكانت نتائجه كما هو موضح بالجدول رقم ( r r ) ) }
$$

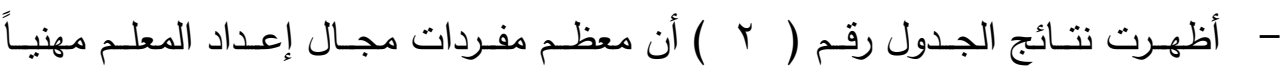
وتخصيصياً وثقافياً قد جاءت في المرتبة الأولي (يتحقق مستوي الرضا بدرجة كبـة كبيرة)

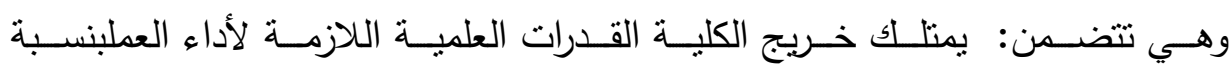

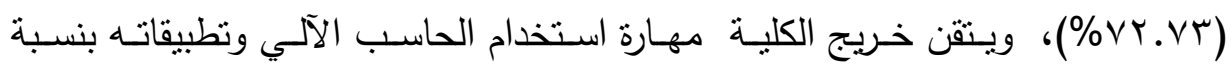

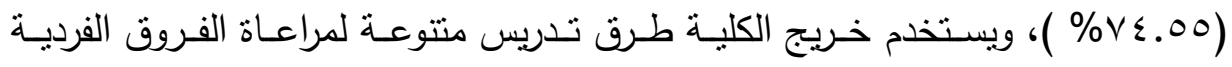

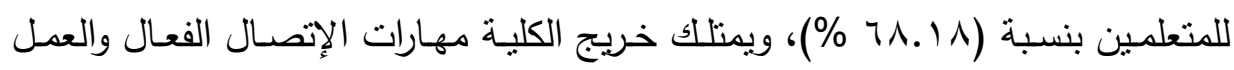

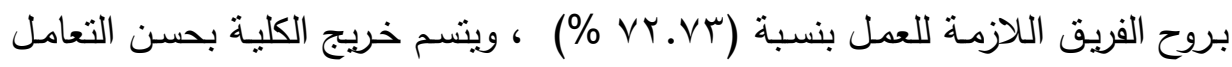

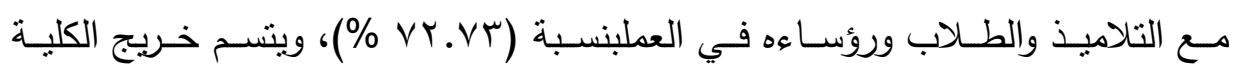

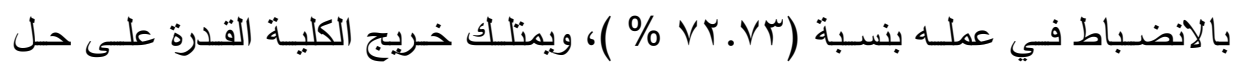

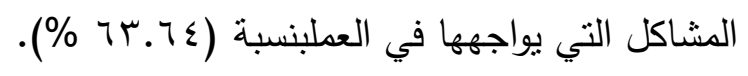

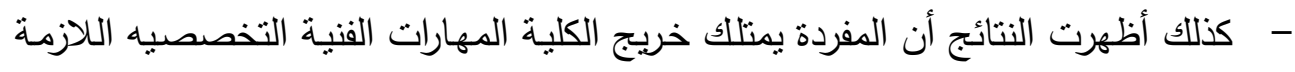

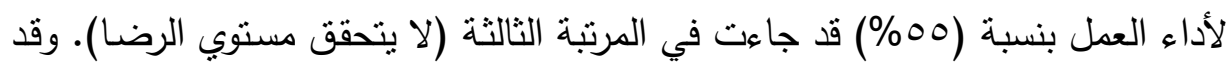

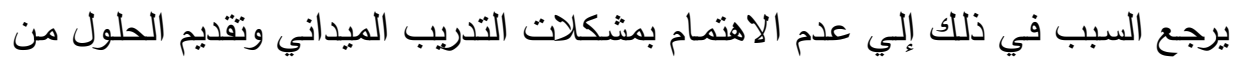
جانب الموجين والمسئولين بكلية التربية

ثانياً: مجال برامج التنمية المهنية للمعلم : تقدم الكلية برامج تساهم في: يركز هذا المحور على مستوي رضا الأطراف المجتمعية وتحديد احتياجاتهم من الكلية

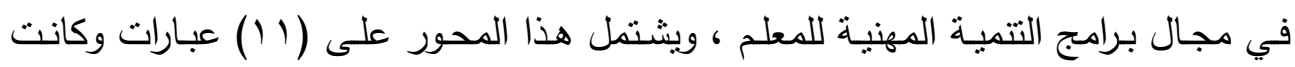
نتائجه كما هو موضح بالجدول رقم ( r r ) )

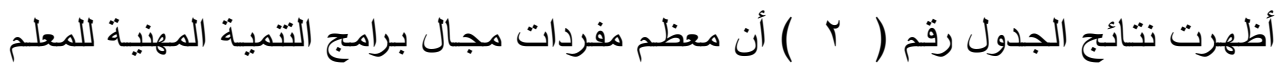

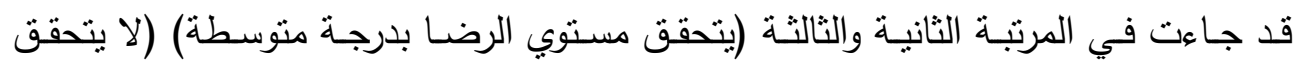
مستوي الرضا) علي التوالي. وهي تتضنمن: 
- - تحسين المهارات التي تسـل القيام بالعمليات التدريسية المطلوبه يتحقق مستوي الرضـا

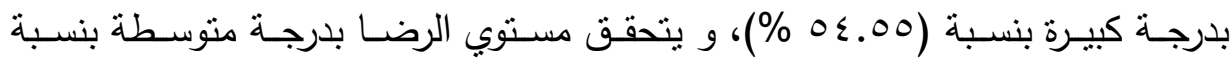

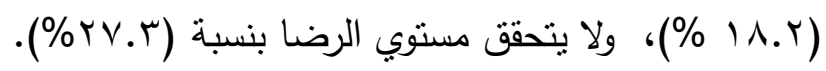

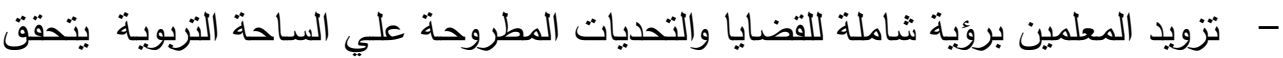

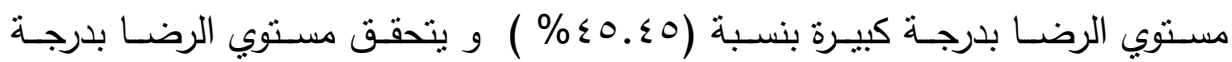

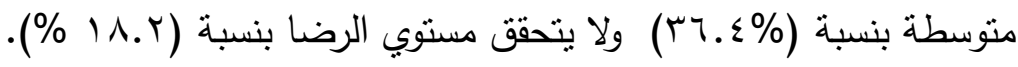

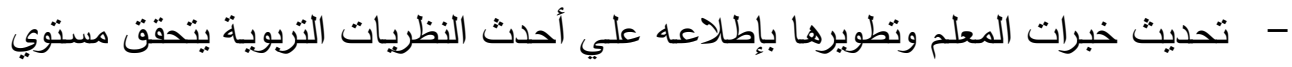

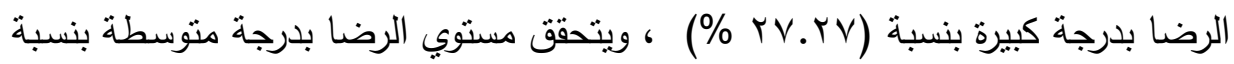

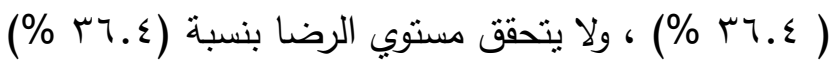
- - تغيير الاتجاهات السلبية للمعلمين نحو مهنة التدريس يتحقق مستوي الرضـا بدرجة كبيرة

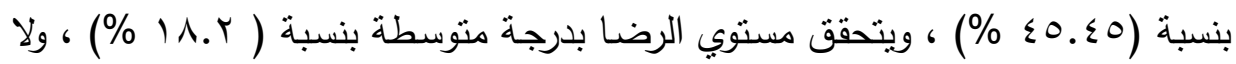

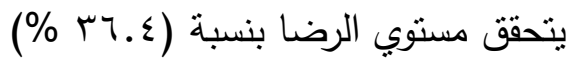
- تبصـر المعلمين بخطط الدولة وتوجهاتها ومشكلات المجتمع والمطلوب منهم يتحقق

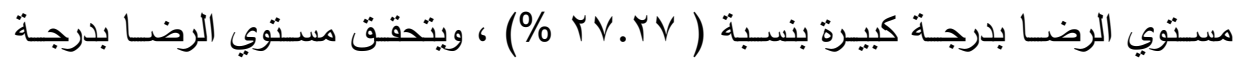

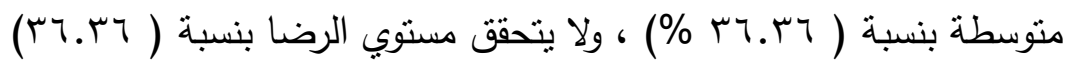

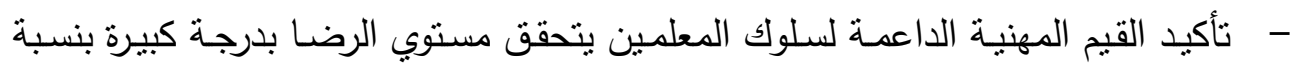

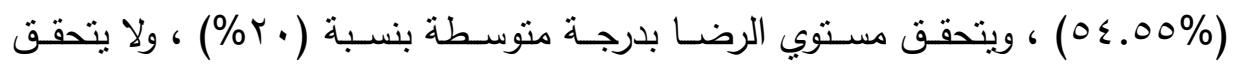

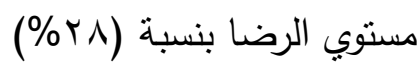

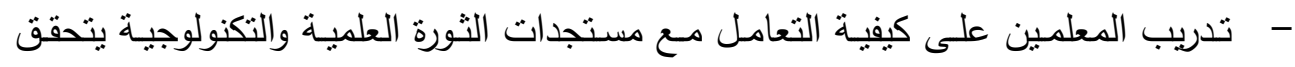
مستوي الرضا بدرجة كبيرة بنسبة (00.0 \% \% ، ويتحقق مستوي الرضا بدرجة متوسطة

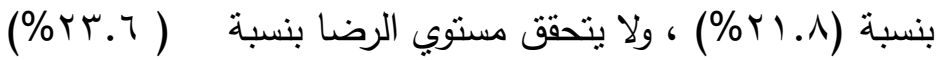
- - تتمية القدرة على استراتيجيات التفكير العلمي والناقد يتحقق مستوي الرضـا بدرجة كبيرة

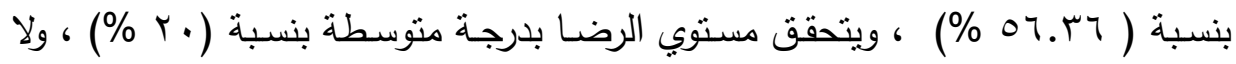
يتحقق مستوي الرضا بنسبة (T.r \% \% 
- - ترسيخ مبدأ التعلم الذاتي لضمان ديمومة الأرتقاء بالمستوي المهني للمعلم يتحقق مستوي

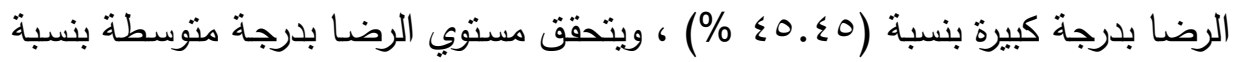

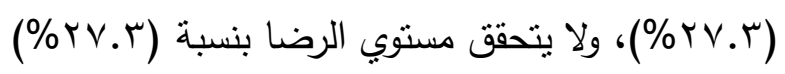

كذلك أظهرت النتائج أن بعض المفردات قد جاءت في المرتبـة الاولي يتحقق مستوي

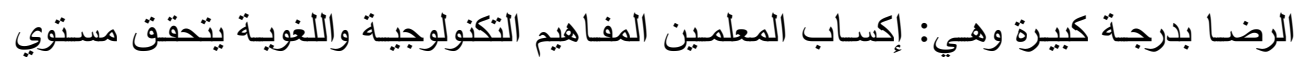

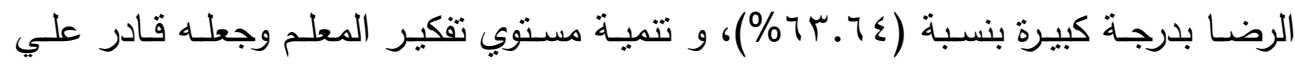
التجديد والابتكار والابداع بنسبة ( . 7\%).

ثالثاً: مجال خدمة المجتمع وتنمية البيئة: يركز هذا المحور على مستوي رضا الأطراف المجتمعية وتحديد احتياجاتهم من الكلية

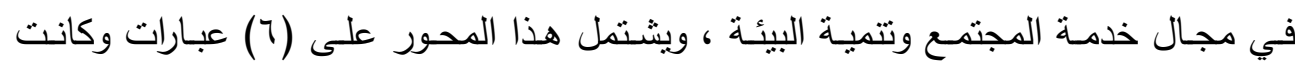
نتائجه كما هو موضح بالجدول رقم ( r r )

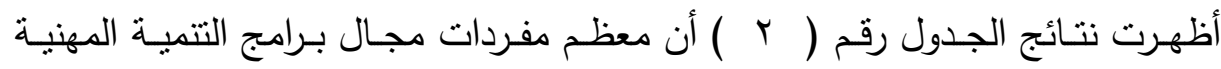

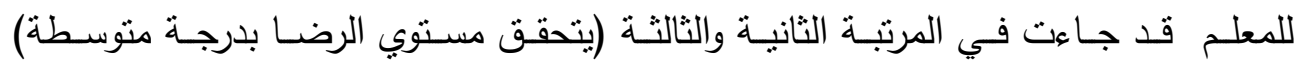
(لا يتحقق مستوي الرضا) علي التوالي. وهي تتضمن: - - تقوم الكلية بممارسـات عملية لحمايـة البيئة يتحقق مستوي الرضـا بدرجة كبيرة بنسبة

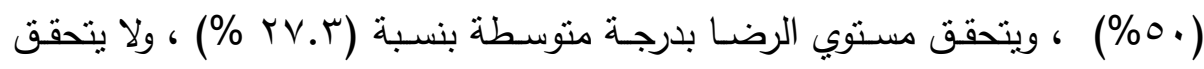
مستوي الرضا بنسبة (V.V. T \%). - - تحصل على المعلومات من الكلية بصورة سهلة وسريعة ودقيقة يتحقق مستوي الرضـا بدرجـة كبيرة بنسبة ( (9 . 0 \% \%) ، ويتحقق مسـتوي الرضـا بدرجـة منوسطة بنسبة

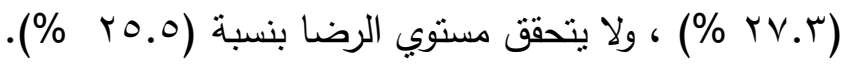
- - تشارك طلاب الكلية في برامج محو الأمية وتعليم الكبار يتحقق مستوي الرضـا بدرجة

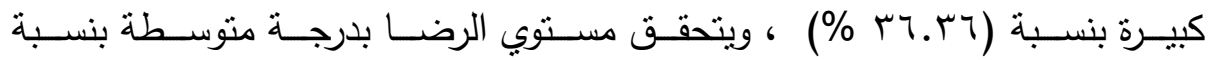
(9 .9 \% \%) ، ولا يتحقق مستوي الرضا بنسبة (0.0 \% \% \%). 
- - تشـارك الأطراف المجتمعيـة في إعداد البرامج التعليميـة يتحقق مستوي الرضـا بدرجـة

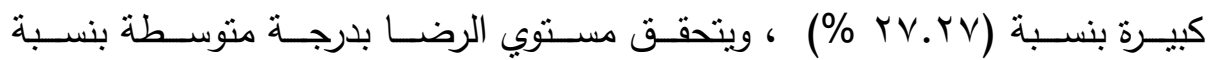

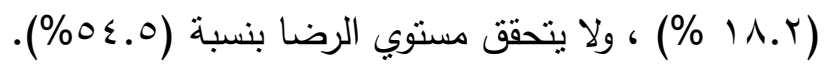

كذلك أظهرت النتائج أن بعض المفردات قد جاءت في المرنبة الاولي يتحقق مستوي الرضــا بدرجـة كبيرةوهـي: توجــ مشـاركة لخريجـي الكليـة فـى المسؤتمرات والندواتبنسـبة (9 . . \%\%)، نوجد مشاركة لمؤستكم فى المجالس الرسمية بالكليةبنسبة (س.VY VY\%).

رابعاً: مقترحات لتحقيق التواصل الفعال بين الكلية والمستفيدين من الخدمة: يركز هذا المحسور على مقترحـات لتحقيق التواصـل الفعـال ببين الكليـة والمسـتفيلين مـن الخدمة، ويشتمل هذا المحور على (V) عبارات وكانت نتائجه كما هو موضح بالجدول رقم (Y): أظهرت نتائج الجدول رقم ( r ) أن مفردات المقترحات جاءت بالمرنبة الأولى ، وقد جاء في مقدمة المقترحات عقد ندوات للأطراف المجتمعية للتعريف بالأنشطة التي تقدمها

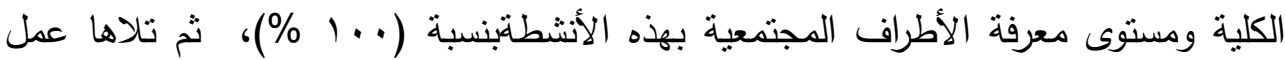

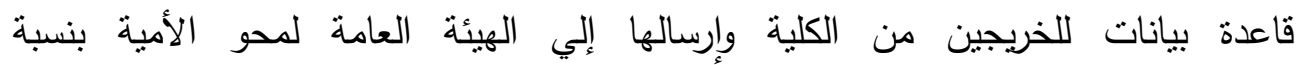
(0.0 (9 \%)، ثم تلاها توفير الكنيات والنشرات الدورية التي تتيح للمشاركين كافة المعلومات التي تمكنهم من المشاركة الفعالة في صناعة القرارتبنسبة (Tr.V\%\%)، ثم تلاها مشاركة مؤسسات المجتمع المدني التي تهنم بحماية البيئة مع الكلية في عمل معسكرات لتعليم الطلاب الجوانب العملية لصيانة البيئة ودورهم تجاه المجتمع بنسبة (19.9\%) ثم تلاها المفرادت الثلاثة التالية بنفس التقدير المئوي ( وأفراد المجتمع للمشاركة في الندوات والمؤتمرات بالكلية لمعالجة قضية مجتمعية ما، تعبين عضو من أعضاء المجتمع المدني في المجالس الرسمية بالكلية، كمنسق بين الكلية ومؤسسات المجتمع المدني، و تشجيع المعلمين علي التدريس في برامج محو الأمية في مقابل منح دبلومة تربوية لأي شخص ذوي مؤهل عال يتمكن من محو أمية . .. فرد علي الأقل. 


\section{r- نتائج التحليل الكيفي للاراسة:}

من خلال إجابة عينة الدراسة عن الأسئلة المفتوحة التي تلي كل محور من محاور الدراسة

$$
\text { يتضح الآتي: }
$$

أولاً: مجال إعداد المعلم مهنياً وتخصيصياً وثقافياً:

- - وتخلصت نتائج تحديد احتياجات المؤسسات التربوية من المواصفات التى ينبغى توافرها

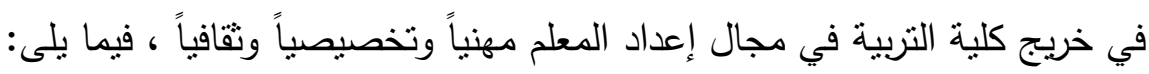
القدرة علي صياغة الهدف السلوكى . مهارة القيادة .

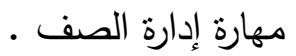

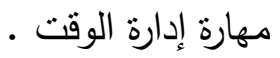
امتلاك مهارات التدريس الجيدة .

تدريس العلوم ، و( الفيزياء- الكيمياء- العلوم البيولوجية ) باللغة الإنجليزية لطلاب التعليم العام بالمرحلة الإعدادية والثانوية. تدريس العلوم لطلاب المرحلة الابتدائية باللغة الإنجليزية. تذريس الرياضيات باللغة الإنجليزية لطلاب التعليم العام بالمرحلة الإعدادية والثانوية. تدريس الرياضيات باللغة الإنجليزية لطلاب المرحلة الابتدائية. إعداد معلم اللغة الإنجليزية للتعليم الابتدائي. الاطلاع علي المادة العلمية. القدرة علي اجراء البحوث . القدرة علي التواصل مع الزملاء والرؤساء وأولياء الأمور .

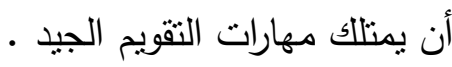
القدرة علي حل المشكلات . التعاون.

التعرف علي مصادر المعلومات والقيم المهنية . 
القدرة علي استخدام وسائل بيئية لتسهيل المعلومات علي الطلاب .

ان يتحلي بالقيم الاخلاقية الحميدة .

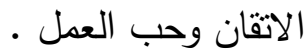

القدرة علي تلبية الاحتياجات النفسية للطلاب .

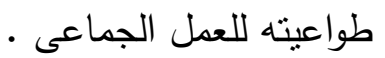

تحسين المستوى المادى لخريج كلية التربية .

ثانياً: مجال برامج التنمية المهنية للمعلم : تقدم الكلية برامج تساهم في: تلخصت نتائج تحديد أنواع الدورات التدريبية التي يمكن لكلية التربية أن تقدمها للمعلمين في الميدان ، وكذلك التى يحتاجها خريج كلية التربية في مجال برامج التتمية المهنية للمعلم، فيما يلى :

دورات للتنريب علي طرق التذريس المختلفة .

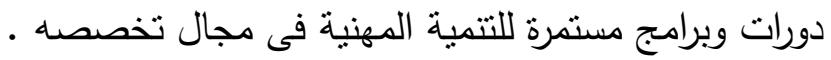

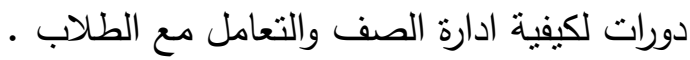

دورات لتحقيق معايير الجودة

دورات تدريبية لإستخدام التكنولوجيا والوسائل التكنولوجية الحديثة فى مجال التدريس.

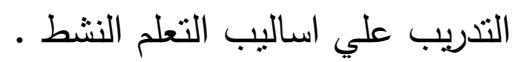

دورات عن كيفية مراعاة الفروق الفردية .

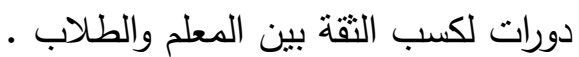

دورات تتمية بشرية .

دورات في مجال الجودة للمؤسسة التعليمية .

دورات نتقيفية .

دورات خاصة بالنواحى الادارية .

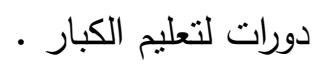

دورات في التواصل مع الصم والبكم وذوى الاحتياجات الخاصة . 


$$
\begin{aligned}
& \text { دورات لتتمية مهارات القراءة . }
\end{aligned}
$$

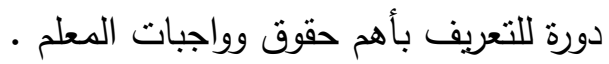

$$
\begin{aligned}
& \text { دورة ICDL }
\end{aligned}
$$

ثالثاً: مجال خدمة المجتمع وتتمية البيئة: وتلخصت نتائج تحديد مقترحات تحسين أداء الكلية لخدمة المجتهـع وتتميـة البيئة،في مجال خدمة المجتمع وتتمية البيئة فيمايلى :

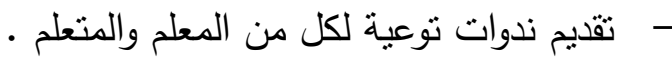

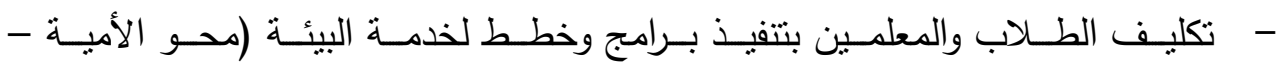

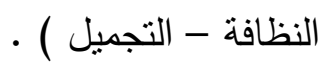

- - التواصـل الجيد والفعـال مـع مؤسسـات المجتمـع والجهات الحكوميـة والعمل وفق خطـة واضحة ومحددة .

- - تدريب الطلاب علي الانضباط والالتزام باللوائح والقوانين المنظمة للعمل . - - مشاركة الكلية في محو الامية للكبار وفي حماية البيئة .

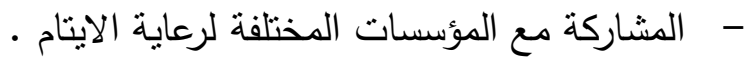
- - دراسة احتياجات سوق العمل للاستفادة من الخريجين -

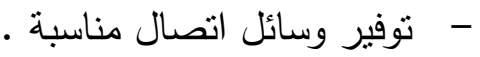

رابعاً:مقترحات لتحقيق التواصل الفعال بين الكلية والمستفيدين من الخدمة: وتلخصت نتائج تقديم مقترحات أخري لتحقيق التواصل الفعال بين الكلية والمؤسسـات التربوية من وجهة نظر افراد العينة، كما يلى : فتح حوار مجتمعى للاستفادة من خبرات الكوادر بالكلية . عقد برامج لنتمية الوعى البيئى والمشاركة الفعالة فى خدمة البيئة . ان يكون البروتوكول بين الطرفين فعال ،علي ان تقوم الكلية بوضـع قواعد للعمل ليل

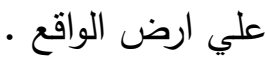


وجـود قســـ داخـل الكليـة والمؤسسـات التربويـة يقـوم بهذا الـدور علـي ان يكـون الأعضاء من ذوى الخبرة في هذا المجال .

وجود وفرة من الكتيبات والنشرات إلكترونيا وورقيا عن حماية البيئة .

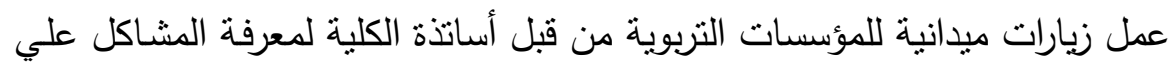

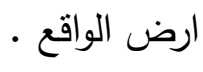

عقد ندوات فعالة بين الكلية والمؤسسات التربوية .

مشاركة ممثل عن كلية التربية فى المجالس الرسمية التى تعقدها المؤسسات التعليمية .

وجود مندوب دائم للتواصل بين الكلية والمؤسسات التربوية .

المشاركة فى الانشطة التى تقوم بها المدرسة .

متابعة المشرفين من داخل الكلية للتربية العملية بشكل اكثر فعالية .

تنبى الكلية قضايا العصر ووضع هذا المفهوم ضمن اهنمامها وموادها ومقرراتها الدراسية .

تحويل ونظوير الجانب النظرى الاكاديمى الي واقع عملي ملموس . 


\section{المراجع}

1. أحمد حسني عبد الغني: دراسة مقارنة لنظم الربط بين التعليم الفني الصناعي وسوق العمل

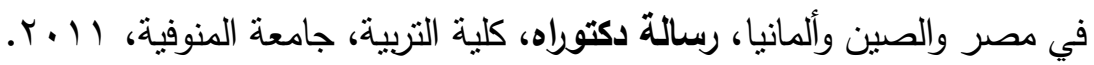

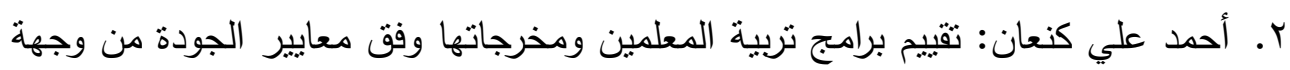
نظر طلبة السنة الرابعة في قسم معلم الصف وأعضاء الهيئة التعليمية، مجلة جامعة

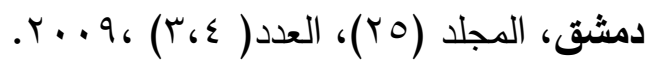

r. أمل رضا عبد المولي: التخطيط الاستراتيجي للتعليم الجامعي لتلبية احتياجات سوق العمل في ضوء خبرات بعض الدول الأجنبية، رسالة ماجستير، كلية التربية، جامعة

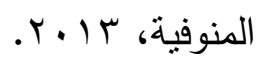

ـ. أميرة خيري علي: روية مقترحة لدعم العلاقة التكاملية بين مؤسسات إعداد المعلم ومدارس التعليم العام بجمهورية مصر العربية، مجلة دراسات تريوية ونفسية، كلية

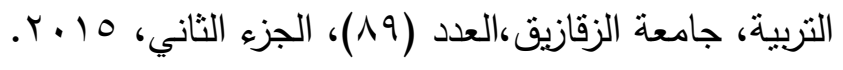

ه. حنان رضوان: تصور استيراتيجي للشراكة بين الجامعة ومؤسسات المجتمع المدني لمعالجة قضايا البيئة.. دراسة حالة علي محافظة القليوبية، مجلة مستقبل التربية

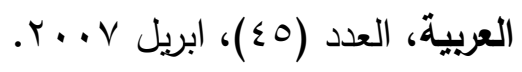

7. سامي عبد السميع نور الدين: دعم العلاقة بين المجتمع ومؤسسة التعليم في ضوء

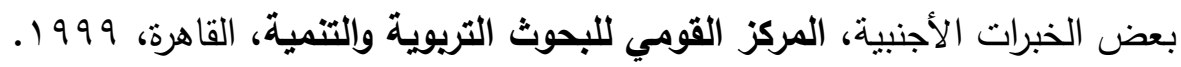
V. سماح زكريا محمد: تصور مستقبلي لتطوير دور الوحدات ذات الطابع الخاص بالجامعة

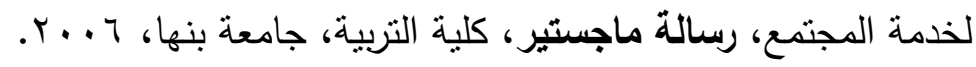
^. صلاح أحمد الناقة، إيهاب محمد أبو ورد: إعدادالمعلموتتميتهمهنيًا في ضوء التهاه التحديات

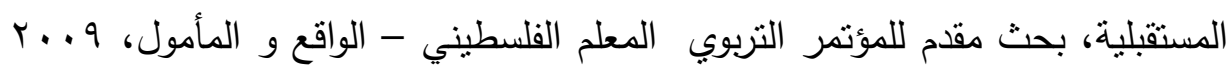
https://www.google.com.eg/search?biw=1366\&bih=655\&q:متاح علي 9. السيد سلامة الخميسي: دور كليات التربية في خدمة المجتمع والبيئةبين.. النجاحات والإخفاقات ، وخيارات المستقبل( دراستة حالة لكلية التربية - جامعة الملك سعود ) متاح علي: https://www.google.com.eg/?gfe_rd=cr\&ei=18H-VqDvH7Kx8wf-olbwBQ\#q 
• (.اللائحة الداخلية لكلية التربية للمرحلة الجامعية الأولى الليسانس والبكالوريوس: اللائحة

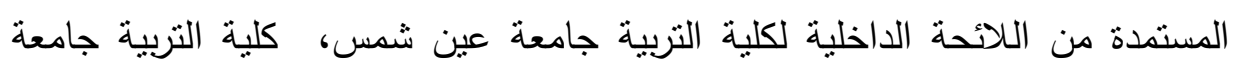

$$
\text { بنها، V. V. V. }
$$

ا (اللائحة الداخلية للاراسات العليا: اللائحة المستمدة من اللائحة الداخلية لكلية التربية

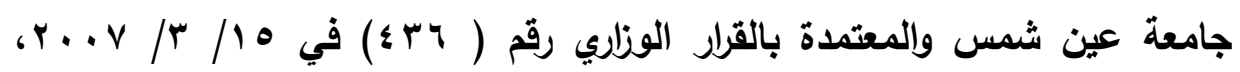

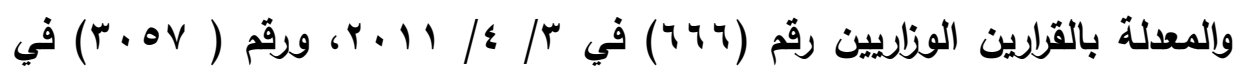

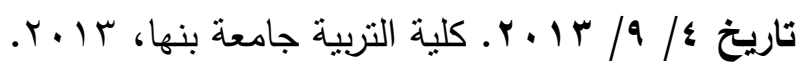
rا .محمد الأصمعي محروس سليم: الإصلاح التربوي وإلثراكة المجتمعية المعاصرة.. من المفاهيم إلي التطبيق، دار الفجر للنشر والتوزبع، القاهرة، 0 . . ب.

با.محمد السيد علي الكسباني : البحث التريوي بين النظرية والتطبيق، سلسلة الفكر

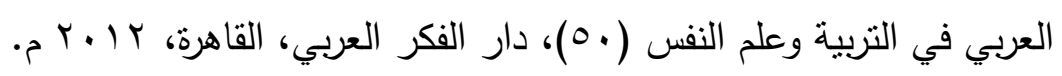
ع ا.وفاء عبد الفتاح محمود: المشاركة المجتمعية في تطوير التعليم قبل الجامعي في داني محافظة القليوبية، رسالة ماجستير، كلية التربية، جامعة بنها، 9 . . . . 